\title{
Economics
}

The Open-Access, Open-Assessment E-Journal

Vol. 12, 2018-62 | October 15, 2018 | http://dx.doi.org/10.5018/economics-ejournal.ja.2018-62

\section{Computational evidence on the distributive properties of monetary policy}

\author{
Siyan Chen and Saul Desiderio
}

\begin{abstract}
Empirical studies have pointed out that monetary policy may significantly affect income and wealth inequality. To investigate the distributive properties of monetary policy the authors resort to an agent-based macroeconomic model where firms, households and one bank interact on the basis of limited information and adaptive rules-of-thumb. Simulations show that the model can replicate fairly well a number of stylized facts, especially those relative to the business cycle. The authors address the issue using three types of computational experiments, including a global sensitivity analysis carried out through a novel methodology which greatly reduces the computational burden of simulations. The result emerges that a more restrictive monetary policy increases inequality, even though this effect may differ across groups of households. In addition, it appears to be attenuated if the bank's willingness to lend is lower. The overall analysis suggests that inequality can constitute valuable information also for central banks.
\end{abstract}

The Matlab file to simulate the model is available from the authors upon request.

JEL C63 D31 D50 E52

Keywords Economic inequality; monetary policy; agent-based models; NK-DSGE models; stock-flow consistency; global sensitivity analysis

\section{Authors}

Siyan Chen, Business School, Shantou University, Daxue Road 243, Shantou, Guangdong, P. R. China

Saul Desiderio, Business School, Shantou University, Daxue Road 243, Shantou, Guangdong, P. R. China, saul@stu.edu.cn, saul1979@libero.it

Citation Siyan Chen and Saul Desiderio (2018). Computational evidence on the distributive properties of monetary policy. Economics: The Open-Access, OpenAssessment E-Journal, 12 (2018-62): 1-32. http://dx.doi.org/10.5018/economicsejournal.ja.2018-62 


\section{Introduction}

Common wisdom about monetary policy holds that its real effects are only temporary and that, consequently, its role be to keep the macroeconomy 'in order' by providing a non-inflationary environment. One logical consequence of this view is that central banks should be as independent as possible from political influence because independence has been shown to promote price stability (e.g. Alesina and Summers, 1993).

Although arguments in favor of independence are convincing, in the long run monetary policy could have deeper implications for the economy than just affecting prices. Among other things, in fact, its potential ability to influence income, wealth and consumption inequality has been argued. This prompts that central banks may possess more social responsibility than usually deemed, and that inequality may well be taken into account when central bankers set their policy goals. In principle, just as it happens for fiscal policy decision-makers, it could even make the case for a more democratic control of monetary policy actions.

Monetary policy can affect inequality through different channels. For example, an expansionary monetary policy that reduces unemployment can also reduce income inequality. In addition, low interest rates decrease capital income, which is relatively more important for richer individuals. As a consequence, income inequality may decline. But at the same time low interest rates boost financial assets prices and therefore increase wealth inequality. On the other hand, a contractionary monetary policy aimed at reducing inflation may well have the opposite effects. ${ }^{1}$

Clearly, the overall effect of monetary policy on economic inequality can hardly be predicted in advance because of the many channels through which it operates. The relatively few empirical studies which have investigated the redistributive effects of monetary policy provide contrasting evidence. Among these, Coibion et al. (2017) find that expansionary monetary policy has decreased both income and consumption inequality in the US, whereas Mumtaz and Theophilopoulou (2017) find the same evidence for the UK. Conversely, Davtyan (2017) finds the opposite result for the US if the top $1 \%$ of the population is included in the analysis. Along the same line is a study of the Bank of England (2012), which also suggests that expansionary unconventional (asset-buying) monetary policies might have increased inequality in the UK. Romer and Romer (1999) found a decrease of inequality and poverty due to expansionary monetary policies in the short run, but their result is quite the opposite in the long run, where it is prudent (non-inflationary) monetary policy that appears to have reduced inequality through price stability. The effect of monetary policy through inflation is considered also by Erosa and Ventura (2002), who find that generally lower-income households are less protected against inflation than higher-income classes; by Doepke and Schneider (2006), who find that rising inflation can redistribute wealth in favor of middle-class households; and by Albanesi (2007), who finds a positive correlation between inflation and income inequality.

Because of the different data-sets, methodologies and time spans considered, and because of the very nature of observational data, the answer provided by empirical works is far from unanimous. Thus, resorting to economic models could contribute to make greater clarity. Indeed, from the theoretical point of view the subject has attracted very little attention, mainly because

1 A detailed taxonomy of the different channels can be found in Nakajima (2015). 
the assumption of representative agents in mainstream methodology is obviously inadequate to address distributional issues. Recent exceptions are NK-DSGE models that introduce some kind of household heterogeneity ('HANK' models) such as Gornemann et al. (2012), Areosa and Areosa (2016), Gornemann et al. (2016), Kaplan et al. (2016) and Sterk and Ravn (2017), which in general find that rising interest rates increase inequality. However, these models can be questioned under different angles. Besides being subject to usual criticisms that apply to mainstream macro models, such as the use of representative agents, perfect rationality and excessive centrality of equilibrium solutions (for a thorough discussion see e.g. Delli Gatti et al., 2011), HANK models also lose some of the appeal which generally characterizes NK-DSGE models as they "typically require heavy computational methods which may obscure intuition and overlook equilibria" (Sterk and Ravn, 2017). But we want to point out that another and more subtle issue has gone unnoticed thus far - namely that NK-DSGE models are inadequate to assess monetary policy. Monetary policy in fact produces real effects on the economy mainly as long as it influences nominal variables, for instance through the 'balance sheet' channel (Bernanke and Gertler, 1995). On the contrary, as NK-DSGE models embody the classical dichotomy through rational expectations, the transmission of monetary policy to the real economy can be attained in this class of models only by introducing nominal stickiness. In other words, in NK-DSGE models monetary policy generates real effects as long as it does not influence nominal variables. We therefore believe that something deeply flawed lies in mainstream macro models.

If inequality and monetary policy are the objects of interest, a valid (if not ideal) alternative to HANK models are agent-based models, as individual heterogeneity is one of their constitutive features. Moreover, this modeling approach can easily accommodate for all the complex relationships that characterize real economies. The principal goal of this paper is therefore to shed some light on the distributive properties of monetary policy through the analysis of artificial data produced by computational experiments in a multi-agent environment. Moreover, the usefulness and advantage of computer simulations is that, unlike empirical studies, they allow to study a given subject in a true ceteris paribus fashion. The second goal of the paper is therefore to assess whether the distributive effects of monetary policy are affected by other variables. In particular, we will consider the role of banks' lending attitude, which is an important channel for the transmission of monetary policy. This is another advantage of our approach over NK-DSGE models, which in general do not include a banking sector. Finally, the third goal of the paper is to provide a methodological contribution, as we will propose a computationally-light approach to global sensitivity analysis.

Our experiments will be conducted in the virtual economic environment generated by a novel agent-based model which builds upon previous works like Delli Gatti et al. (2011), Delli Gatti and Desiderio (2015) and Chen and Desiderio (2018). An important characteristic of our model is stock-flow consistency (SFC), which has witnessed increasing application in agent-based literature in recent years (e.g. Cincotti et al., 2010; Delli Gatti and Desiderio, 2015; Riccetti et al., 2015; Caiani et al., 2016). SFC, basically consisting in the implementation of precise accounting rules, is of particular importance when money and credit are explicitly introduced into the model and monetary policy is considered. Besides, SFC provides a correct link between income and wealth, whose evolution constitutes the main focus of the paper. SFC is therefore introduced 
to increase the degree of realism of the model as well as its ability to simulate monetary policy interventions.

In the model we are going to present, households have two different income sources: wages and capital income (the latter being generated by the return on bank deposits). Monetary policy affects income and wealth inequality through the so-called 'income channel', as it influences both wages (along with unemployment) and the return on financial assets. However, as the relative weight of the two income sources is generally different for different households, the impact of monetary policy will vary from household to household. Thus, the overall effect can hardly be determined in advance, also because it is the result of the interaction between monetary policy and other mechanisms like the availability of credit. We point out that one important limitation of our model is that the effect of monetary policy on asset values is not considered. Hence, changes in wealth inequality are mainly a consequence of changes in income inequality. Another limitation is given by the absence of households' debts, which have probably played a non-secondary role in the increase of inequality witnessed in the last decades. Basically, in the model we will not consider the so-called 'portfolio channel'.

In recent years the analysis of inequality has been a hot topic in the context of agent-based macroeconomics. For instance, Desiderio and Chen (2016), Riccetti et al. (2016) and Russo et al. (2016) study how functional and personal income distributions are affected by financial factors. The role of monetary policy is considered by Dosi et al. (2013) and Dosi et al. (2015). These two works, however, differ substantially from ours as they study the impact of inequality on monetary policy, whereas we will focus on the opposite direction of causality, i.e. the effect of monetary policy on inequality.

The paper continues as follows. In Section 2 we describe the model and in Section 3 we run simulations. In spite of its relative simplicity, we will show that our model is able to match a good deal of empirical evidence, performing particularly well in replicating business cycle stylized facts. In Section 4 we will study the distributive properties of monetary policy. To this scope we will use three different techniques: a policy experiment, a local sensitivity analysis and a global sensitivity analysis. The latter will be carried out employing an original approach aimed at economizing on the computational effort necessary to perform this kind of analysis. All the techniques employed suggest that a more restrictive monetary policy increases economic inequality, in line with findings obtained in HANK literature. But our inequality analysis is conducted at a finer level of detail than mainstream models: we will in fact consider different classes of households and the role of the banking sector. Finally, Section 5 concludes.

\section{The model}

We consider a dynamic economy populated by $F$ firms, $H$ infinitely lived households (workersconsumers) and one commercial bank, while we leave both the Government and the central bank unmodeled. All agents take decisions on the basis of limited private information. The households supply labor, buy consumption goods and hold deposits at the bank. The firms demand labor, produce and sell consumption goods, demand bank loans and hold deposits. The bank receives deposits and extend loans to firms. There are therefore four markets: for labor, consumption 
goods, bank loans, and deposits. Agents enter their relevant markets and interact with a number of partners according to a decentralized search and matching process. All transactions are therefore characterized by persistent uncertainty.

The economy evolves over time for a number of periods $t=1 \ldots T$. Each period the same sequence of events takes place:

1. Firms decide the amount of output to be produced, the level of desired workforce and the price to be charged.

2. Firms post their vacancies along with wage offers.

3. Unemployed workers randomly contact a given number of firms to get a job.

4. Newly employed workers sign a job contract lasting $D$ periods.

5. Firms pay the wage bill. If internal financial resources are insufficient, firms may borrow from the bank.

6. The bank extends loans to credit-worthy firms and pays interests on households' deposits.

7. Households decide their consumption budget and enter the goods market. Each consumer randomly chooses a fixed number of firms.

8. Firms collect revenues and validate debt commitments to the bank.

9. Firms not able to validate debt commitments go bankrupt and are replaced by an equal number of new firms. The initial capital of new firms is financed by taxes levied on households' deposits.

10. As a consequence of firms' bankruptcies, the bank registers a bad debt (non-performing loan).

11. Households update their wealth according to their income and consumption expenditure.

\subsection{The balance sheets}

Agents are characterized by state variables summarized by their balance sheets. The evolution of these variables satisfies the rules of a complete accounting system, which ensures consistency between flows and stocks (assets and liabilities). This consistency implies model closure, in the sense that no external resource is incorrectly added to the system and no internal resource is lost. This property is clearly important in itself, but it is even more so to our analysis because it assures that income and wealth inequality do not undergo undue alterations. In addition, changes in the balance sheets play a relevant role in the transmission of monetary policy (Bernanke and Gertler, 1995).

Table 1 shows the aggregate balance sheets for each group of agents.

$D_{h}$ and $D_{f}$ are households and firms' deposits (liquid assets), $L$ represents bank loans, $E_{h}, E_{f}$ and $E_{b}$ are households, firms and the bank's equity (net worth) respectively; $H$ is high powered 


\begin{tabular}{ccccc}
\hline & Households & Firms & Bank & Total \\
\hline Deposits & $D_{h}$ & $D_{f}$ & $-\left(D_{h}+D_{f}\right)$ & 0 \\
Reserves & & & $H$ & $H$ \\
Loans & & $-L$ & $L$ & 0 \\
\hline Total & $E_{h}$ & $E_{f}$ & $E_{b}$ & $H$ \\
\hline
\end{tabular}

Table 1: Balance sheets

money (HPM). There is no currency in circulation so that the only use of HPM is as a liquidity buffer for the bank (reserves). Hence, for simplicity we set $H=0$.

In the aggregate assets and liabilities must sum to zero, thus the following accounting identity holds:

$$
E_{h}+E_{f}+E_{b}=H=0
$$

Agents' behavior determines the dynamics of stocks. Market transactions producing flows of funds are illustrated by Table $2 .^{2}$

$C$ is consumption, $w N$ is the wage bill ( $w$ is the wage rate and $N$ is employment), $Y$ is total production, $I$ is the change in inventories, $i$ is the loan interest rate and $r$ is the return on bank deposits. As firms invest only in inventories, the flow of current savings must be equal to the change in inventories:

$$
S_{h}+S_{f}+S_{b}=I
$$

where $S_{h}=\Delta E_{h}=\Delta D_{h} ; S_{f}=\Delta E_{f}=\Delta D_{f} ; S_{b}=\Delta E_{b}$. As we will explain later, we assume that firms do not retain unsold goods $(I=0)$. Hence, total savings are always equal to zero.

As already stated, we assume that there is no currency in circulation as firms and households keep always all their liquid assets in form of bank deposits. This implies a causal relation going from loans to deposits. In fact, every transaction between firms and households is implemented through bank accounts without any actual exchange of currency outside the bank. Hence, the level of deposits changes only when a new loan is granted, an outstanding loan is repaid and interests are paid to, or paid by, the bank.

\subsection{Firms}

Due to uncertainty, firms have only an imperfect knowledge of market conditions and, consequently, they have to form expectations $D_{i t}^{e}$ on demand. Because firms do not accumulate inventories (see below), the desired quantity of goods to supply $Y_{i t}^{*}$ is set at the level of expected demand. However, actual production $Y_{i t}$ may differ from the desired level $Y_{i t}^{*}$ if firms are constrained on the credit market or on the labor market.

Though firms produce the same homogeneous consumption good, imperfect competition caused by uncertainty and consumer search costs entails that they have some degree of market

\footnotetext{
2 Items representing outflows are identified by the minus sign.
} 


\begin{tabular}{ccccc}
\hline & Households & Firms & Bank & Total \\
Goods & $-C$ & $Y=C+I$ & & $I$ \\
Wages & $w N$ & $-w N$ & & 0 \\
New loans & & $\Delta L$ & $-\Delta L$ & 0 \\
Loan interests & & $-i L$ & $i L$ & 0 \\
Deposit interests & $r D_{h}$ & & $-r D_{h}$ & 0 \\
New deposits & $-\Delta D_{h}$ & $-\Delta D_{f}$ & $\Delta D$ & 0 \\
\hline Savings & $S_{h}$ & $S_{f}$ & $S_{b}$ & $I$ \\
\hline
\end{tabular}

Table 2: Flow of funds

power. The firm's strategy is therefore the couple $\left(P_{i t}, Y_{i t}\right)$, where $P_{i t}$ is the firm's price level at time $t$.

At price $P_{i t}$, and given the competitors' prices, the actual demand for firm $i$ is $D_{i t}$, which may differ from production $Y_{i t}$. The difference between production and demand shows up in inventories $I_{i t}=Y_{i t}-D_{i t}$.

We assume the goods to be perishable and non-storable. This means that firms cannot take inventories to the next period to satisfy future demand. Ignoring the inventory cycle is clearly a limitation of the model, but it can be considered as quite a realistic approximation of modern economies, whose GDP is mainly composed of non-storable services.

Although goods cannot be stored, inventories are used by firms as market signals: positive inventories, in fact, signal that demand has been overestimated (excess supply), whereas no inventory accumulation $\left(I_{i t}=0\right)$ indicates that demand has been underestimated (excess demand) or exactly estimated (equilibrium).

\section{Price and quantity decisions}

At the beginning of each period, the generic firm $i$ adjusts the price $P_{i t}$ or the desired quantity to supply $Y_{i t}^{*}$ to adapt to changing market conditions. We assume that the firm cannot simultaneously change price and quantity. This is of course a simplifying assumption, but at the same time it is consistent with the empirical evidence on price and quantity adjustment of firms over the business cycle (Kawasaki et al., 1982; Bhaskar et al., 1993).

The firm's strategies depend both on its internal conditions and on market signals. The relevant information at time $t$ for firm $i$ consists of the average market price $P_{t-1}$ (which is a proxy for the prices of firm $i$ 's competitors) and of the individual excess demand/supply recorded in the previous period and captured by unsold inventories $I_{i t-1}$.

The firm adjusts the price according to the following adaptive rule-of-thumb:

$$
P_{i t}= \begin{cases}P_{i t-1}\left(1+\eta_{i t}\right) & \text { if } I_{i t-1}=0 \text { and } P_{i t-1}<P_{t-1} \\ P_{i t-1}\left(1-\eta_{i t}\right) & \text { if } I_{i t-1}>0 \text { and } P_{i t-1} \geq P_{t-1}\end{cases}
$$

where $\eta_{i t}$ is an idiosyncratic random variable uniformly distributed on the support $\left(0, h_{\eta}\right)$. Moreover, price $P_{i t}$ is supposed to be not lower than $P_{i t}^{l}$, i.e. the minimum price at which firm $i$ is able 
to cover its average costs:

$$
P_{i t} \geq P_{i t}^{l}=\frac{W_{i t}+r_{i t} L_{i t}}{Y_{i t}},
$$

where $W_{i t}$ is the current wage bill and $r_{i t} L_{i t}$ is the service on outstanding debts. The logic of this rule is that excess demand $\left(I_{i t-1}=0\right)$ is conducive to upwards price revisions only when the firm is competitive (price below the average market price). In this case the firm can raise the price in order to widen its profit margins.

The firms decides to update the desired activity level as follows:

$$
Y_{i t}^{*}=\left\{\begin{array}{lll}
Y_{i t-1}\left(1+\rho_{i t}\right) & \text { if } I_{i t-1}=0 \text { and } P_{i t-1} \geq P_{t-1} \\
Y_{i t-1}\left(1-\rho_{i t}\right) & \text { if } I_{i t-1}>0 \text { and } P_{i t-1}<P_{t-1}
\end{array}\right.
$$

where $\rho_{i t}$ is an idiosyncratic shock uniformly distributed on the support $\left(0, h_{\rho}\right)$.

The rationale behind above rules is that positive inventories (excess supply) trigger downwards quantity revisions only when the price is already low enough (below the average market price). In this case the firm does not want to further decrease the price for not compromising its profit margins.

\section{Vacancies and wages}

Firms carry on production by means of a linear production function using labor as the only input. For firm $i$ we have

$$
Y_{i t}=\alpha N_{i t} \quad \alpha>0,
$$

where $\alpha$ is labor productivity and $N_{i t}$ is the employed workforce. For simplicity, we assume that technology is uniform across firms and time like for instance in Assenza et al. (2015). Hence, neglecting productivity growth entails that our framework is best interpreted as a model of the economic activity at business cycles frequencies.

From Eq. (6) we get the desired workforce $N_{i t}^{d}$, i.e. demand for labor:

$$
N_{i t}^{d}=\frac{Y_{i t}^{*}}{\alpha}
$$

where $Y_{i t}^{*}$ is the desired level of production.

The firm then posts vacancies $V_{i t}$ equal to the difference between the desired workforce and the operating workforce $N_{i t-1}$, given by the workers still employed at firm $i$ at the beginning of period $t$.

Alongside vacancies, firm $i$ has to decide whether to update the wage level to be paid to its employees. The wage offered by the firm at time $t$ is determined according to the following rule:

$$
w_{i t}= \begin{cases}w_{i t-1}\left(1+\xi_{i t}\right) & \text { if } V_{i t}>0 \\ w_{i t-1} & \text { if } V_{i t}=0\end{cases}
$$

where $w_{i t-1}$ is the wage offered to the workers employed at time $t-1$ and the variable $\xi_{i t}$ is an idiosyncratic shock uniformly distributed on the support $\left(0, h_{\xi}\right)$. Because of labor homogeneity, we assume that all the workers employed by firm $i$ at time $t$ will receive the same wage $w_{i t}$. 
The downward rigidity of nominal wage embodied in rule (8) reflects the abundant empirical evidence on firms' wage-setting policies. Numerous surveys have shown in fact that wage cuts are unlikely even during recessions, mainly because they could increase workers' turnover and decrease labor effort (Campbell and Kamlani, 1997; Bewley, 1999; Daly et al., 2013).

\section{External finance}

At the beginning of period $t$ firm $i$ is endowed with liquid resources $D_{i t}$, i.e. its bank deposits. Following the "pecking order" theory on business capital structure (e.g. Myers and Majluf, 1984), we assume that the wage bill $W_{i t}$ is first financed by internal resources and then, if these are not enough, by external funds provided by the bank. The demand for new bank loans therefore is given by

$$
B_{i t}^{d}=\max \left(W_{i t}-D_{i t}, 0\right),
$$

with the corresponding interest rate $r_{i t}$ given by Eq. (20) in Section 2.4.

The firm may be rationed by the bank if its credit rating $C R_{i t}$ is too low. Consequently, the amount of new loans $B_{i t}$ actually supplied by the bank may be lower than credit demand (see Section 2.4).

Once the firm has received the loan, if total resources are still not sufficient to pay for the wage bill, the firm is allowed to fire redundant workers at zero costs.

\section{Entry and exit}

After the closure of the consumption goods market (see Section 2.3), firm $i$ has sold quantity $Q_{i t}$ at price $P_{i t}$. Accordingly, its revenues are $R_{i t}=Q_{i t} P_{i t}$. Unsold production is eventually destroyed at zero costs.

The firm then computes its profits $\pi_{i t}$, equal to revenues minus wage bill and interests:

$$
\pi_{i t}=R_{i t}-W_{i t}-r_{i t} L_{i t} .
$$

Hence, firm $i$ 's net worth $A_{i t}$ will evolve according to the law

$$
A_{i t+1}=A_{i t}+\pi_{i t} .
$$

At the end of each period, the firm has to pay back a fraction $\tau$ of its outstanding debt, which therefore will evolve according to the following rule:

$$
L_{i t+1}=(1-\tau) L_{i t}+B_{i t} .
$$

In principle, above proportional repayment scheme imposes a higher burden on the first time steps after a firm has borrowed money. However, this bias is mitigated by the fact that firms generally ask for loans several times to finance production. Hence, not necessarily the average per-period repayment decreases monotonically over time.

The total cash flow generated by all the transactions occurred during period $t$ is

$$
C F_{i t}=R_{i t}+B_{i t}-W_{i t}-\left(r_{i t}+\tau\right) L_{i t},
$$


whereby we get the law of motion of the firm's liquid resources, i.e. bank deposits:

$$
D_{i t+1}=D_{i t}+C F_{i t} \text {. }
$$

The firm is declared insolvent and exits the market if it is not able to serve its debt to the bank. Hence, the firm may remain active even if it is "technically" in default, that is if $A_{i t+1}<0$, provided that deposits $D_{i t+1}$ are positive. When the firm defaults, its employed workers get fired.

The bankrupt firm is replaced by a new one, whose initial capital is financed by the Government through a flat tax $\psi$ levied on households' wealth. This mechanism is not particularly realistic but is functional to our purposes: firstly, it is important to assure stock-flow consistency without affecting wealth inequality and, secondly, it determines a negative impact on the economy by reducing households' spending capacity.

Price $P_{i t+1}$ and wage $w_{i t+1}$ of the new firm are set to the level of their corresponding average market values $P_{t}$ and $w_{t}$. Moreover, the new firm inherits from the defaulted one a share $\kappa$ of its outstanding debts $L_{i t}$, whereas the remaining part $(1-\kappa)$ is absorbed by the bank's capital as bad debt.

The perfect replacement of bankrupt firms is a working hypothesis to keep total firms' population constant, but it can be motivated on the basis of two widely accepted stylized facts: first, in established industry the number of firms tend to settle down around a roughly constant level; second, the inflows and outflows of firms show strong positive correlation (Geroski, 1991). What we are doing, therefore, is to implicitly assume a correlation equal to 1.

\subsection{Households}

We suppose that households are made up of a single worker/consumer. Workers supply one unit of labor per period, search for a job if unemployed, buy consumption goods and save their money in the form of bank deposits.

Once a period, the bank pays interests on households' deposits at the policy rate $i_{t}$. Basically, we model deposits as a risk-free interest-bearing financial investment and, therefore, we use them as a proxy for an unmodeled "financial sector". Thus, deposits constitute one of the channels through which monetary policy exerts its influence on income and wealth inequality: when in fact changes in the policy rate affect the return on deposits, monetary policy also affects households' capital income.

We suppose that only unemployed workers search for a new job (on-the-job search is excluded mainly for simplicity, but also see below). The unemployed enter the labor market sequentially, and contact a given number of firms to get a job. Moreover, the unemployed worker $j$ has a reservation wage given by

$$
w_{j t}^{r}= \begin{cases}w_{j t-1} & \text { if employed in } t-1 \\ w_{j t-1}^{r}\left(1-\chi_{j t}\right) & \text { if unemployed in } t-1,\end{cases}
$$

where $\chi_{j t}$ is a random shock uniformly distributed on the support $\left(0, h_{\chi}\right)$. Eq. (15) therefore implies that workers who have been inactive longer will have in general lower reservation wages and will be more prone to accepting lower wages. 
In general, because of uncertainty demand and supply of labor do not coincide and involuntary unemployment, therefore, may occur. The unemployed worker $j$ randomly sends $M$ applications to as many firms. If his/her contract has just expired, one of the applications is sent to his/her last employer. Once the $M$ contacted firms have revealed their wage offers, those paying wages below worker $j$ 's reservation wage are discarded. Subsequently, the applicant worker chooses, among the remaining firms that still have open vacancies, the one offering the highest salary. The newly employed worker and the firm sign a fixed-term job contract lasting $D$ periods.

Workers with an active contract can be fired only in case the firm's funds are not sufficient to pay for the wage bill. If this is not the case, therefore, on average every period a share $1 / D$ of job contracts expires, and the newly-unemployed workers will search for a new employer. Consequently, although on-the-job search is ruled out, the reciprocal of the contract duration can be interpreted as the probability for a worker to change job.

Before the consumption goods market opens, households receive their wage from the firms (if employed) and the interests from the bank. Hence, we can define total income (labor income plus capital income) of individual $j$ at time $t$ as:

$$
I_{j t}= \begin{cases}i_{t} D_{j t}+w_{j t} & \text { if } j \text { is an employed worker } \\ i_{t} D_{j t} & \text { if } j \text { is an unemployed worker }\end{cases}
$$

where $D_{j t}$ are household $j$ 's deposits at the beginning of period $t$. Given available financial resources $D_{j t}+I_{j t}$, the consumer allocates a share $c \leq 1$ to consumption and the remaining part to savings. The consumption budget is therefore defined as

$$
C_{j t}=c\left(D_{j t}+I_{j t}\right) \text {. }
$$

For simplicity we suppose the share $c$ (i.e. the marginal propensity to consume out of wealth) to be the same for all households.

Consumers randomly enter the goods market and, because of search costs, visit only a fixed number $Z$ of firms, one of them being the largest (in terms of production) firm visited in the previous period. We assume consumers to adopt this sort of "preferential attachment" mechanism in order to minimize the probability to be rationed.

Each consumer seeks to implement the desired consumption plan starting from the firm charging the lowest price among the selected firms. If goods available at the first firm are not enough, the consumer will turn to the second cheapest firm, and so on. Because of uncertainty, therefore, households may not be able to purchase all the desired quantity of goods.

Finally, the wealth (i.e. deposits) of individual $j$ at the end of time $t$ is defined as

$$
D_{j t+1}=D_{j t}+I_{j t}-C_{j t},
$$

where $I_{j t}$ is given by Eq. (16) and $C_{j t}$ is the expenditure on consumption.

\subsection{The bank}

The bank has three important functions: it is the center of the payment system, supplies credit to firms and pays interests on households' deposits. By its last function the bank basically acts as a reduced-form financial system through which households can invest their savings. 
When a firm is in short supply of liquid resources to pay wages, it will ask for a bank loan $B_{i t}^{d}$ (see Eq. (9)). The bank signs with firm $i$ a long-term debt contract, stating the interest rate $r_{i t}$ and the share $\tau$ of the principal to be repaid every period. For simplicity we suppose that the share $\tau$ is the same for every borrower.

The flow of new credit $B_{i t}$ is granted by the bank to firm $i$ according to the following adaptive rule-of-thumb:

$$
B_{i t}= \begin{cases}B_{i t}^{d} & \text { if } C R_{i t}>\theta \\ 0 & \text { if } C R_{i t} \leq \theta\end{cases}
$$

where $C R_{i t}$ is the firm's credit rating and $\theta$ is the parameter which regulates the bank's lending attitude. The higher the parameter $\theta$, therefore, the more frequent credit rationing will be.

The firm's credit rating at time $t$ is given by 1 minus its probability of default. This probability can be determined in many different ways, for example through the estimation of a Logit model as in Assenza et al. (2015). However, in order to keep things simple we suppose that the bank computes the probability of bankruptcy simply as the firm's relative frequency of default over the window of the last $\Phi$ periods, where $\Phi$ is a parameter. ${ }^{3}$ Hence, the bank will resume lending to firm $i$ only if the latter's credit rating increases above the threshold $\theta$.

The interest rate $r_{i t}$ is determined as a mark-up over the policy rate $i_{t}$ set by a central monetary authority:

$$
r_{i t}=i_{t}\left(1+\mu\left(\lambda_{i t}\right)\right) .
$$

The mark-up in turn is an increasing function $\mu(\cdot)$ of the borrower's leverage $\lambda_{i t}$. Function $\mu(\cdot)$ is the hyperbolic tangent, whereas the firm's leverage is defined as

$$
\lambda_{i t}=\frac{L_{i t}+B_{i t}^{d}}{D_{i t}} .
$$

Equation (20) is based on the theory of the "external finance premium" (Bernanke and Gertler, 1989; 1990), stating that in presence of asymmetric information the interest rate increases with the borrower's financial fragility (here straightforwardly captured by the leverage $\lambda_{i t}$ ).

At the end of the period the bank calculates its profits:

$$
\pi_{t}^{b}=\sum_{i \in \Omega} r_{i t} L_{i t+1}-B D_{t},
$$

where $\Omega$ is the bank's loan portfolio and $B D_{t}$ is the bank's bad debt (non-performing loans) recorded at the end of the period. As explained in Section 2.2, bad debt is defined as a fraction $(1-\kappa)$ of bankrupt firms' outstanding debts.

Total bank credit evolves according to the following law of motion:

$$
L_{t+1}=(1-\tau) L_{t}+\sum_{i \in \Theta} B_{i t}-B D_{t},
$$

where $\Theta$ is the set of firms that borrowed in period $t$.

Finally, the law of motion for the bank's equity can be defined as

$$
E_{t+1}=E_{t}+\pi_{t}^{b} \equiv L_{t+1}-D_{t+1} .
$$

3 For instance, if the firm has defaulted twice during the periods $t-\Phi, \ldots, t-1$, we have $C R_{i t}=(\Phi-2) / \Phi$. 


\begin{tabular}{lll}
\hline Parameter & Description & Value \\
\hline$T$ & Number of periods & 500 \\
$F$ & Number of firms & 100 \\
$H$ & Number of workers & 600 \\
$Z$ & Number of firms visited by a consumer & 2 \\
$M$ & Number of labor applications & 4 \\
$D$ & Job contract length & 8 \\
$c$ & Marginal propensity to consume & 0.8 \\
$h_{\eta}$ & Maximum growth rate of prices & 0.1 \\
$h_{\rho}$ & Maximum growth rate of quantities & 0.1 \\
$h_{\xi}$ & Maximum growth rate of wages & 0.05 \\
$h_{\chi}$ & Maximum \% decrease of reservation wages & 0.05 \\
$\psi$ & Recapitalization coefficient & 0.01 \\
$i_{t}$ & Policy rate & 0.01 \\
$\theta$ & Credit rating threshold & 0.2 \\
$\tau$ & Debt repayment rate & 0.05 \\
$\Phi$ & Defaulting window & 10 \\
$1-\kappa$ & Share of bad debt & 0.05 \\
\hline
\end{tabular}

Table 3: Parameters.

\section{Simulation and validation}

In this Section we are going to show the general properties of the model. We start with a sample simulation of 500 periods using the parameter values reported in Table 3, and then we present some robustness checks. The aim of this Section, therefore, is to validate our model by confronting its properties with comparable empirical evidence. In spite of its simplicity, the model is able to replicate several stylized facts both at macro and micro level.

Fig. 1 shows six time series relative to a representative simulation. In our model business cycles are not the consequence of exogenous aggregate shocks but are caused by a combination of idiosyncratic random shocks and non-linearities. Bounded-rational individual decisions and decentralized interactions produce an alternation of periods of economic expansions and recessions with no tendency to settle down to some long-run equilibrium (Panel 1(a)). The unemployment rate (Panel 1(b)), although not very realistic in absolute value, closely follows the business cycle. This cyclical behavior cannot be explained in terms of microeconomic frictions such as downward nominal wage rigidity and search costs (which are fixed), but is the product of coordination failures within and between markets. In fact, the close similarity between the evolution of unemployment and unsold production (that we do not report) signals the contemporaneous occurrence during recessions of excess supply for both labor and goods and, therefore, points in the direction of a Keynesian (demand-driven) interpretation of unemployment.

A key variable in shaping fluctuations is firms' cash flow. During expansions, in fact, unemployment drops, wages rise and firms build up debts to finance increasing production. As long as 


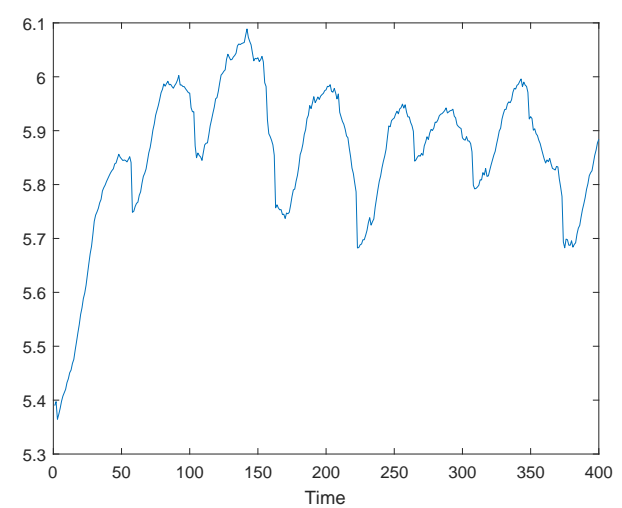

(a)

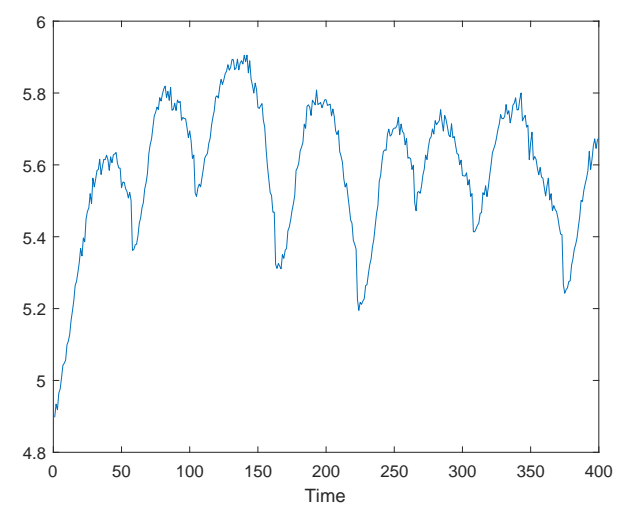

(c)

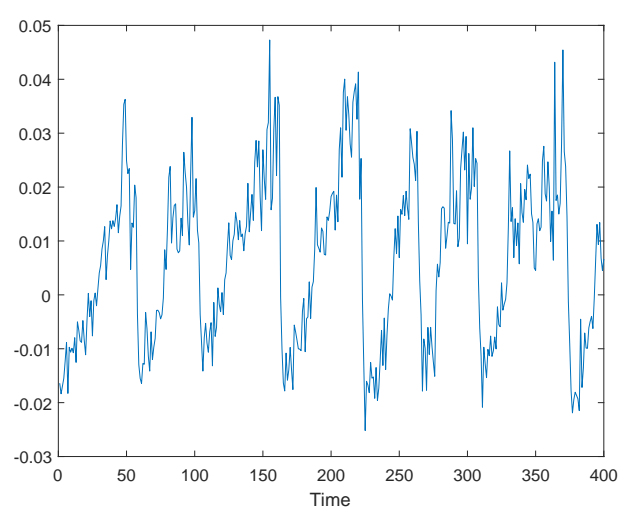

(e)

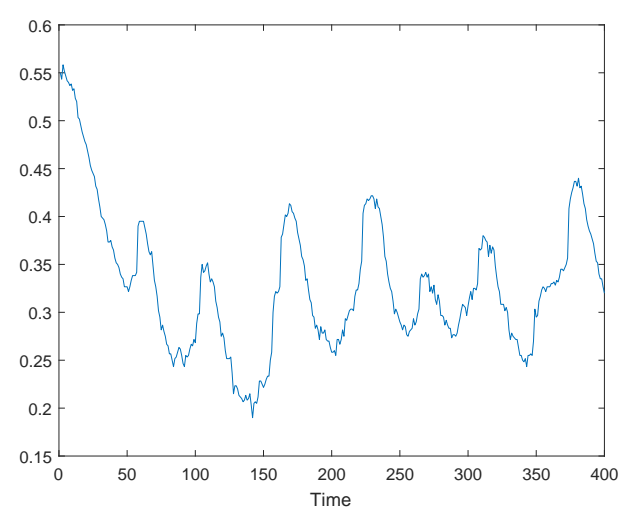

(b)

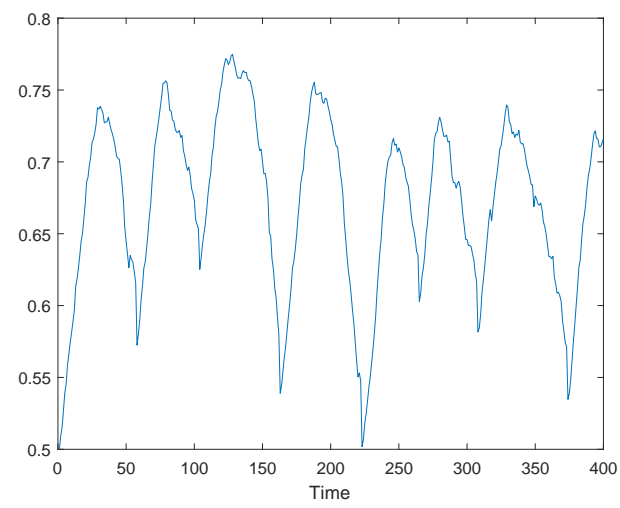

(d)

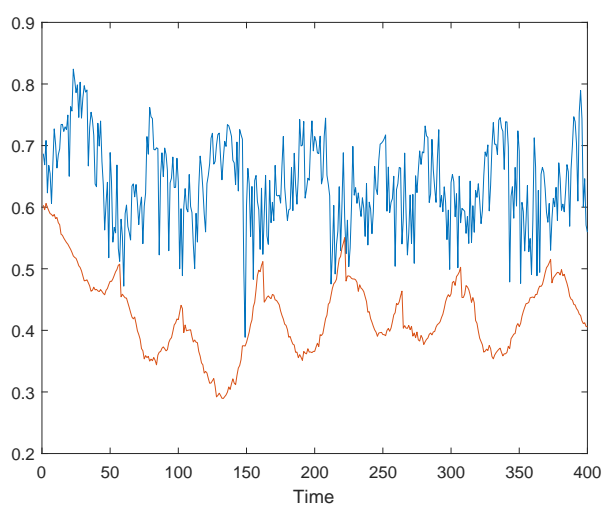

(f)

Figure 1: (a): Real output (on logarithmic scale); (b): Unemployment rate; (c): Consumption; (d): Real wage; (e): inflation rate; (f): Gini coefficients for wealth (blue line) and income (red line). 


\begin{tabular}{llllllllll}
\hline Lag & -4 & -3 & -2 & -1 & 0 & +1 & +2 & +3 & +4 \\
\hline GDP & .4248 & .5560 & .6955 & .8496 & 1 & .8496 & .6955 & .5560 & .4248 \\
& $(.0455)$ & $(.0392)$ & $(.0312)$ & $(.01833)$ & $(0)$ & $(.01833)$ & $(.0312)$ & $(.0392)$ & $(.0455)$ \\
Cons & .5336 & .6173 & .6993 & .7669 & .8362 & .7088 & .5574 & .4090 & .2644 \\
& $(.0468)$ & $(.0431)$ & $(.0380)$ & $(.0304)$ & $(.0212)$ & $(.0297)$ & $(.0385)$ & $(.0425)$ & $(.0469)$ \\
Unem & -.3514 & -.4750 & -.6093 & -.7627 & -.9283 & -.8263 & -.7148 & -.5963 & -.4731 \\
& $(.0495)$ & $(.0441)$ & $(.0364)$ & $(.0257)$ & $(.0132)$ & $(.0242)$ & $(.0353)$ & $(.0406)$ & $(.0455)$ \\
CPI & -.5365 & -.5198 & -.4757 & -.3915 & -.2547 & -.1089 & .0233 & .1307 & .2119 \\
& $(.0749)$ & $(.0791)$ & $(.0801)$ & $(.0805)$ & $(.0817)$ & $(.0812)$ & $(.0787)$ & $(.0742)$ & $(.0689)$ \\
\hline
\end{tabular}

Table 4: Cross-correlations between the cyclical component of GDP at time $t$ with those at time $t+$ lag of (a): Real GDP; (b): Consumption; (c): Unemployment rate; (d): CPI. Averages over 100 simulations (standard errors in parentheses).

revenues allow firms to validate their financial commitments with the bank, production continues to expand. However, rising costs and accumulation of debts reduce firms' cash flow, eventually increasing the rate of default. If the number of bankrupted firms is large enough, or if big firms are among them, aggregate production starts shrinking and unemployment increases. Then, the subsequent loss of employment causes a reduction in households' spending that negatively reverberates on other firms' sales and profits. Furthermore, this vicious cycle is exacerbated by a 'financial accelerator' mechanism: bankruptcies, in fact, lower firms' credit worthiness and leads to credit rationing by the bank (Eq. 19). However, recessions have also an important function: they wipe less efficient and more indebted firms out. This natural selection mechanism makes the economy financially sounder and, eventually, leads to a new expansion phase.

We now show the model properties at business-cycle frequencies. We compare artificial and empirical cyclical components of four variables: real GDP, real consumption, unemployment rate and CPI. Cyclical components are extracted by applying the Hodrick-Prescott filter with smoothing parameter set at 1600. Empirical data are post-war U.S. seasonally-adjusted quarterly time series, retrieved from FRED database. ${ }^{4}$ Fig. 2 shows the results of a co-movement analysis exercise: against each value of lag on the $x$-axis we plot the correlation between the cyclical component of GDP at time $t$ with the cyclical component of the other variables at time $t+l a g$ (with a negative lag corresponding to a lead). We can see that artificial cross-correlations are more pronounced than the observed ones, but their patterns are very similar. Less satisfactory is the result for labor productivity (computed as the ratio between total production and total employment) and real wage (which we omit to report). The former in fact, although able to reproduce the pattern of real data, shows cross-correlations substantially smaller than the empirical counterparts. On the contrary, the latter features a strong (and leading) pro-cyclicality which we can barely find in real time series.

To assess the robustness of above results, we also calculate the average cross-correlations for the same set of variables over 100 independent simulations. Table 4 shows that the averages are quite close to the cross-correlations of the representative simulation. Moreover, the Monte Carlo standard errors shown in parentheses are small, proving that our results are robust.

Finally, we end our business cycles analysis by reporting in Table 5 the Monte Carlo averages of the first-order autocorrelations of the cyclical components of the four variables, showing that

4 We used the files GDPC1, PCECC96, UNRATE and PCECTPI, U.S. Bureau of Economic Analysis, retrieved from FRED, Federal Reserve Bank of St. Louis; https://fred.stlouisfed.org/series/GDPC1, March 13, 2018. 


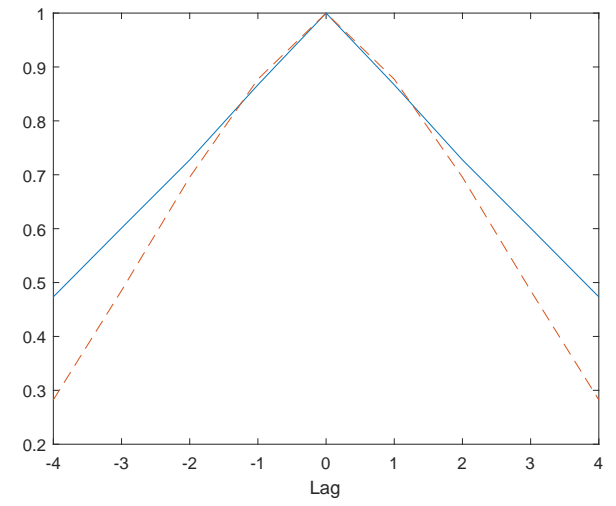

(a)

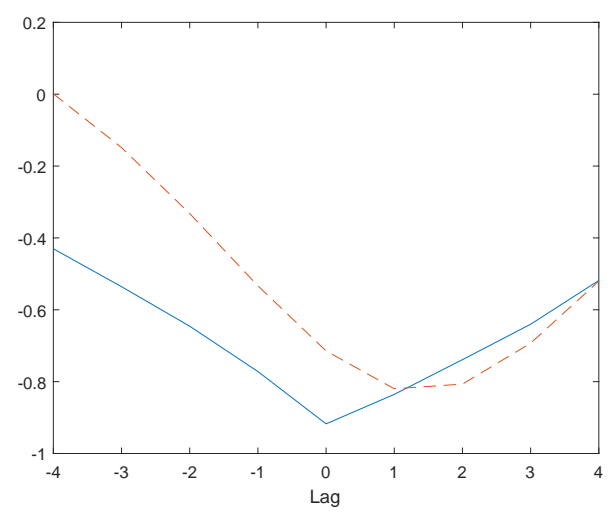

(c)

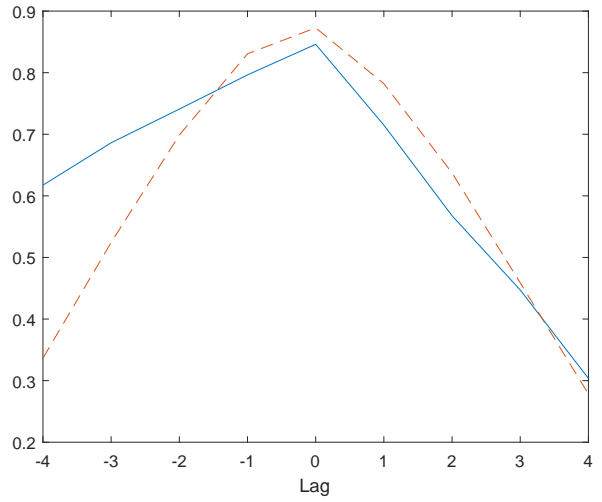

(b)

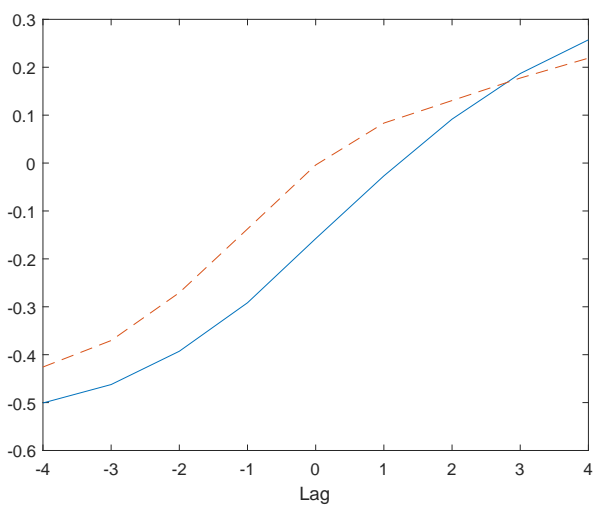

(d)

Figure 2: Cross-correlations for simulated (continuous line) and observed U.S. time series (dashed line). The pictures show the correlation between the cyclical component of GDP at time $t$ with those at time $t+l a g$ of (a): Real GDP; (b): Consumption; (c): Unemployment rate; (d): CPI. 


\begin{tabular}{c|cccc}
\hline & GDP & Consumption & Unemployment & CPI \\
\hline Observed & 0.8773 & 0.8977 & 0.8992 & 0.8675 \\
Simulated & 0.8496 & 0.7238 & 0.8374 & 0.9489 \\
\hline
\end{tabular}

Table 5: First-lag autocorrelation of cyclical components. Averages over 100 simulations.

the agreement between simulated and real data is rather satisfactory. In this case, the agreement is good also for labor productivity and real wage (which we do not report).

In terms of replication of stylized facts our model works quite well also at lower aggregation levels. Fig. 3 reports three well-known statistical regularities describing the relationship between business cycles and labor market dynamics, which we calculate for the representative simulation after discarding the first 100 transient periods. Panel (a) shows the Phillips Curve, featuring a strong and statistically significant negative correlation (-0.6128) between inflation rate and unemployment rate. Panel (b) shows a negative relationship between the output growth rate and the unemployment growth rate - i.e. an Okun curve (correlation of -0.8607). The third emerging regularity is the Beveridge curve (Panel (c)), i.e. a negative relationship between the rate of vacancies (the ratio between the number of job openings and the total number of workers) and the unemployment rate. Also in this case the correlation between the two variables, although not very strong $(-0.3936)$, shows the correct sign and is once again statistically significant. In addition, Panel (d) shows the households' wealth distribution, which coherently with empirical observations exhibits positive skewness and a fat right tail.

At a lower level of aggregation the model replicates, at least qualitatively, also some empirical regularities concerning job flows. We find in fact that unemployment is positively correlated to long-term unemployment (defined as the workforce that has been unemployed for more than three periods); layoffs and hirings, i.e. job destruction and job creation, have strong positive correlation both in levels and in differences; layoffs show higher volatility and are more correlated to unemployment than hiring (Blanchard and Diamond, 1990; Davis et al., 1996).

In conclusion, although relatively simple, the model is able to reproduce a good deal of stylized facts at different levels of aggregation. Hence, in the next Section we are going to employ it as a computational laboratory to study the distributional effects of monetary policy.

\section{Monetary Policy and inequality}

In this Section we are going to assess the effect of monetary policy on personal income and wealth inequality. Changes in monetary policy will be captured by changes in the policy rate $i_{t}$, and the two transmission mechanisms are the return on households' financial investments and the bank's loan rate. Inequality will be measured through two indexes. One is the Gini coefficient, which will also be computed for three different groups of households: the bottom $50 \%$, the middle $40 \%$ and the top $10 \%$ of the distribution. The other index is the ratio $S S$ of the cumulative income (or wealth) belonging to the top $20 \%$ households to the cumulative income (or wealth) belonging to the bottom $20 \%$. In both cases, the higher the indexes, the higher the inequality. 


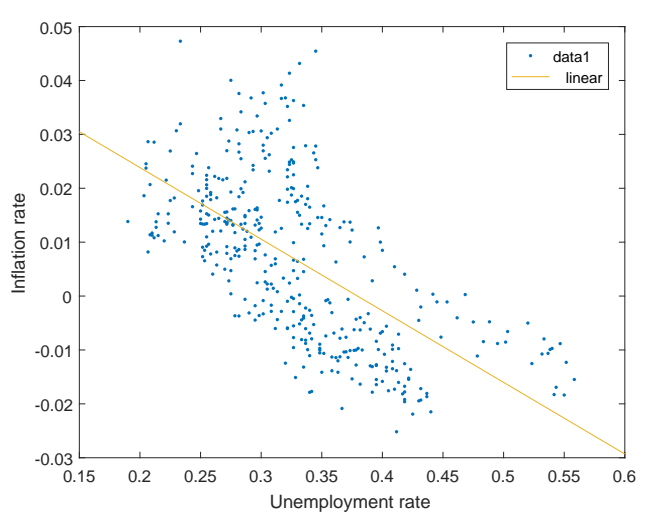

(a)

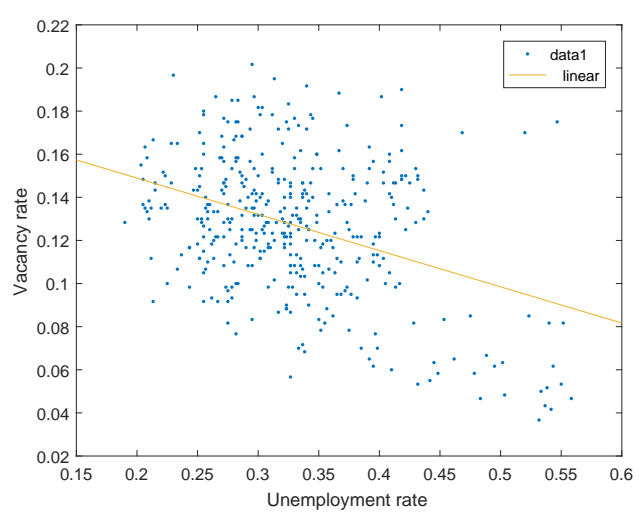

(c)

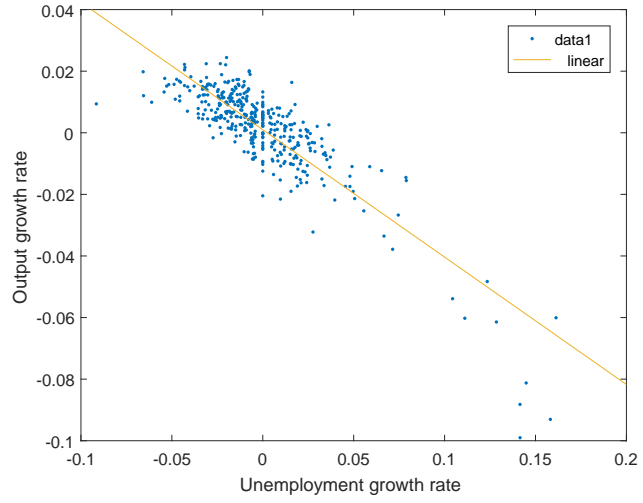

(b)

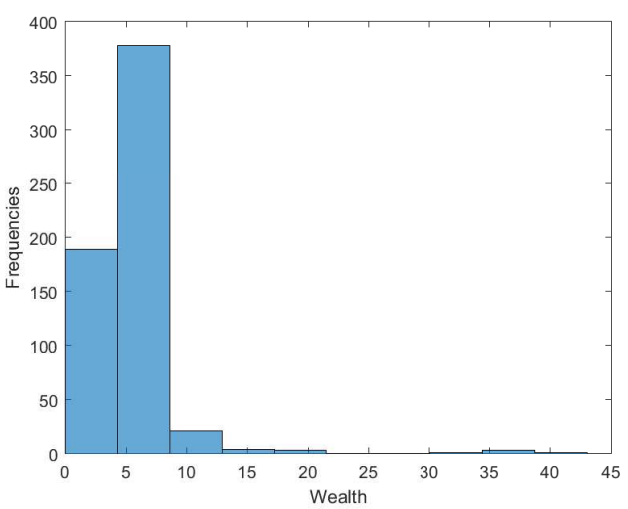

(d)

Figure 3: (a): Phillips curve, (b): Okun curve, (c): Beveridge curve, (d): Wealth distribution at $t=500$.

In the following we will make use of three kinds of analysis: first, in Section 4.1 we will perform a policy experiment simulating a more restrictive monetary policy intervention; second, in Section 4.2 we will perform a local sensitivity analysis exercise involving only the policy rate and, finally, in Section 4.3 we will conduct a global sensitivity analysis aimed at assessing how monetary policy distributive properties are influenced by the bank's lending attitude.

Before turning to the results, we want to remark how inferring causality in agent-based models may be a delicate issue. Unlike mainstream micro-founded models, in fact, in multi-agent frameworks there is in general no one-to-one relationship between micro and macro variables. Consequently, the lack of clear causal links between emergent macro-phenomena and individual behavioral equations makes the interpretation of the results quite an arduous task. Nonetheless, we can expect a rising interest rate to increase capital income and therefore consumption by the rich. However, higher rates affect negatively the supply side of the economy, as they reduce firms' cash flows and increase the default rate, which on its turn triggers credit rationing. Simulations confirm the intuition. When looking at the data, we can in fact identify three main macro effects produced by the policy shock: unemployment increases, both average wage and wage dispersion 
fall (as in general firms paying higher wages are more likely to fail) and capital income increases. We therefore believe that the impact of monetary policy on inequality passes through the composition of these three effects, which in addition seem to have different weight according to the group considered.

\subsection{A Policy experiment}

In this Section we show the consequences of a restrictive monetary policy. We will consider two scenarios: in the first one the policy interest rate is fixed and equal to $1 \%\left(i_{t}=0.01 \forall t\right)$, whereas in the second scenario a policy shock occurs at time 301 , when the rate is increased to $2 \%$. For both scenarios we will run 100 independent Monte Carlo simulations, and then we will consider the average across simulations.

Figs. 4 and 5 show the evolution of Gini coefficient relative to income and wealth respectively, whereas Fig. 6 shows the $S S$ ratio. Qualitatively, the results are the same. In Panel (a) of Fig. 4 we can see that the Gini index for the overall income distribution decreases after the interest rate is raised to $2 \%$ (red line). Hence, the restrictive policy intervention reduces income inequality. This overall effect can be broken down into the partial effects on the three subgroups of households, which show heterogeneous responses to the policy shock. Panel (b) shows in fact that inequality increases for the bottom 50\%. This group is made up of unemployed (mostly) and employed workers with little or no capital income. Hence, inequality increases because unemployment increases (so labor income becomes zero for many of the households belonging to this class). Panel (c) reports the Gini for the middle 40\%. This group is mainly made up of employed workers with some capital income who are not hit by increasing unemployment. At the same time, the decrease of wages lower the differences in labor income, whereas capital income remains grossly the same. It is no surprise therefore that inequality decreases for this group. The same is true for the top $10 \%$ group, constituted by employed workers with large capital incomes. ${ }^{5}$ Also in this case, increasing inequality due to increasing capital income is totally offset by falling wages. Similar patterns are displayed by wealth, with inequality increasing for the bottom $50 \%$ and decreasing for the wealthier groups.

We now repeat the same experiment, with the difference that at time 301 the policy rate is increased to 4\%. Again, for both scenarios we will consider the averages across 100 simulations. The results for the income Gini index are reported in Fig. 7: unlike the previous experiment, after the shock inequality increases for all the three sub-groups. In particular, after a short period in which the Gini goes down, inequality surges also for the wealthier groups. Basically, the rich get richer because the higher return on deposits amplifies the differences in capital income (refer to Eq. (16)). This is particularly true for the middle-income class, which is initially the most homogeneous group and then experiences the largest increase in inequality. The long-run dynamics of inequality is however less clear for the top class, which displays first a sharp decrease

\footnotetext{
5 The composition in terms of income and wealth of the three groups is consistent with the extensive empirical evidence reported by Piketty (2014), according to which the share of wealth belonging to the bottom 50\% group is in general no more than 5\%, while the top $10 \%$ group may own a share as large as $90 \%$ (like in Europe at the beginning of the 20th century).
} 


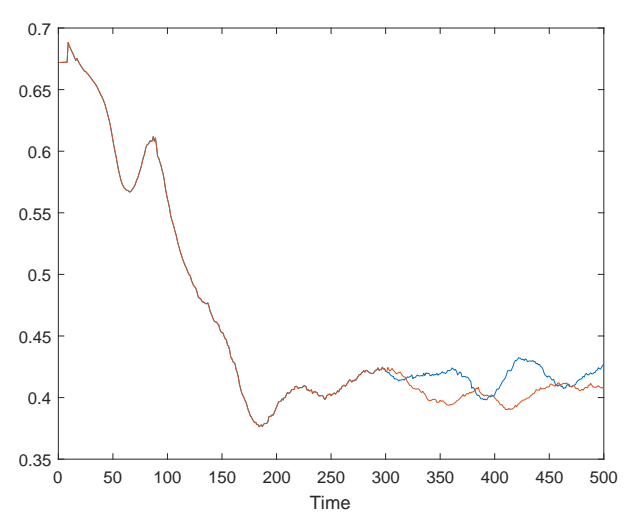

(a)

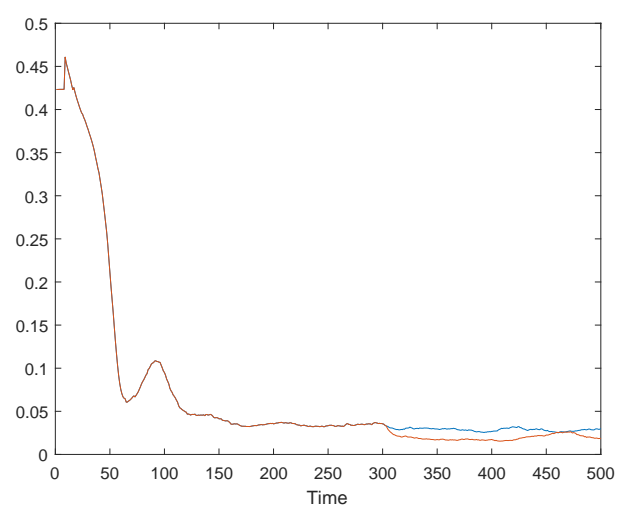

(c)

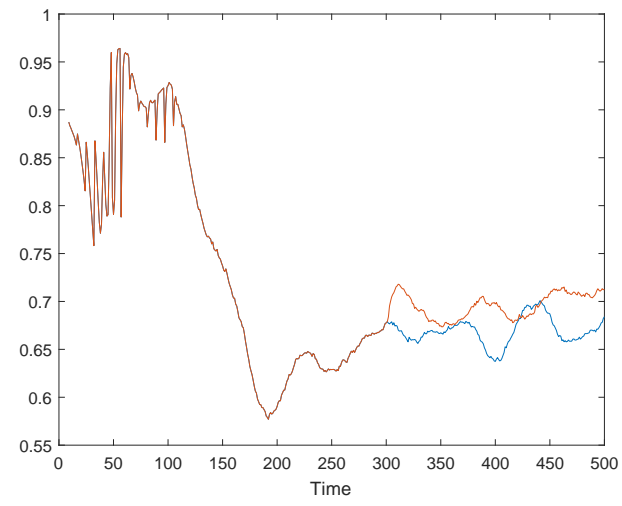

(b)

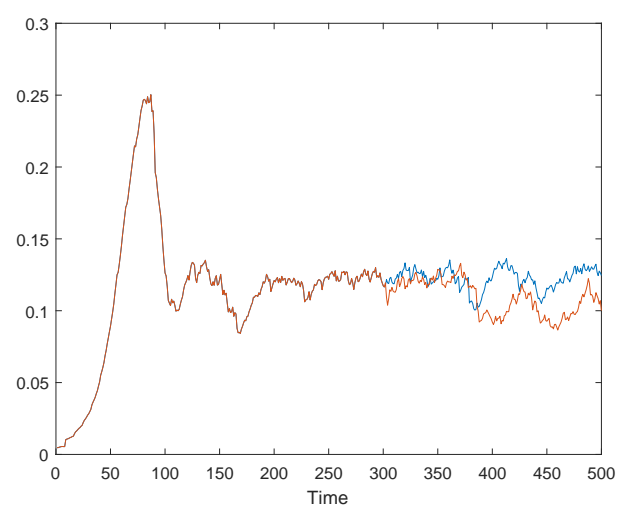

(d)

Figure 4: Shock 2\%, Gini coefficient for income. Panel (a): total; (b): bottom 50\%; (c): middle 40\%; (d): top 10\%. Blue line: no shock; red line: shock at $t=301$. Averages over 100 simulations. 


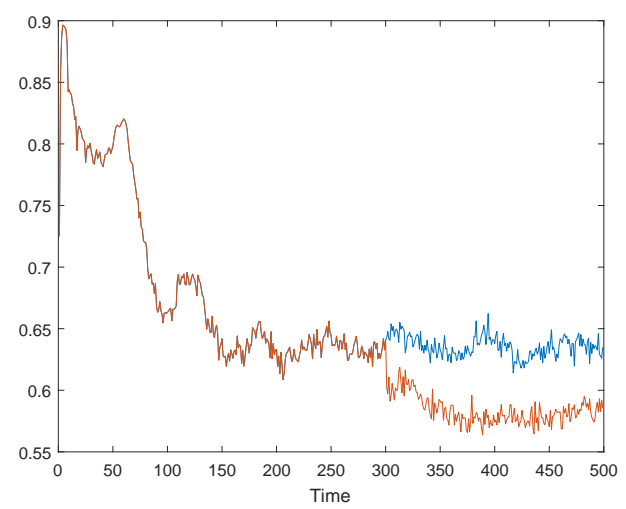

(a)

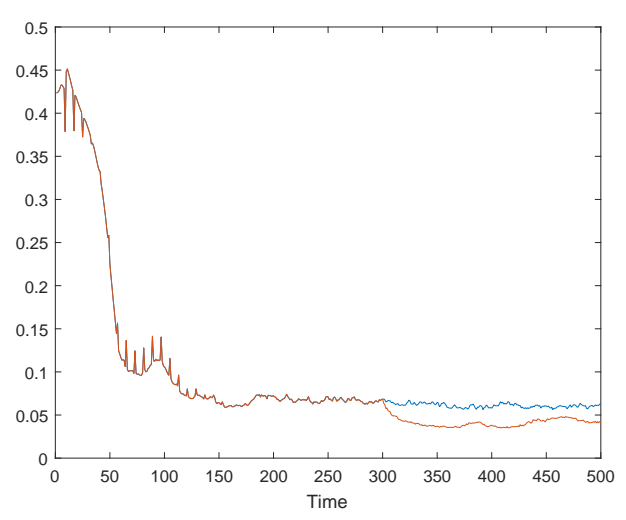

(c)

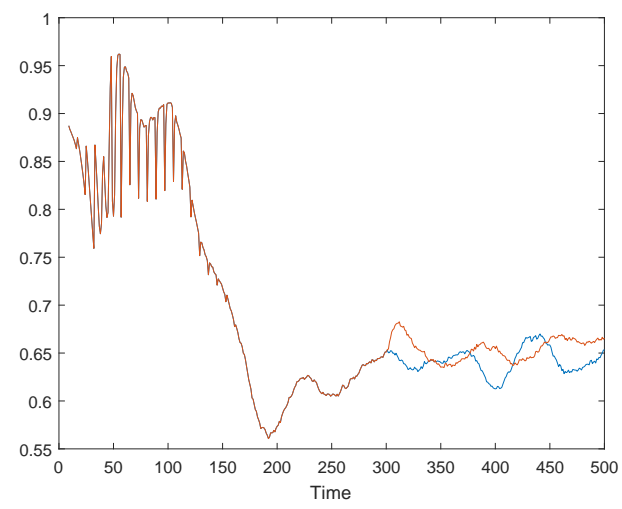

(b)

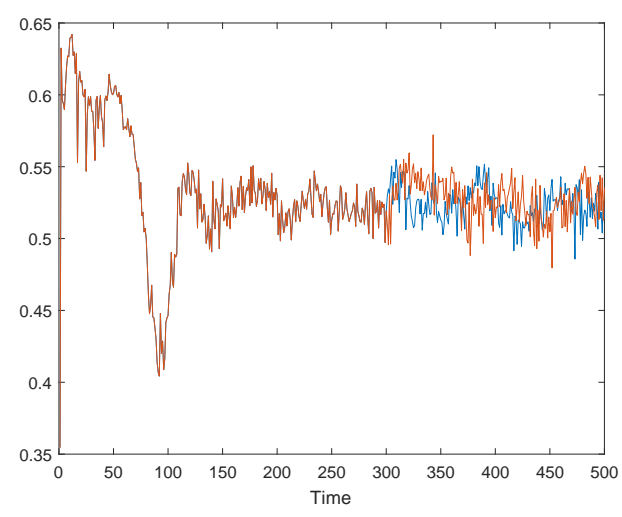

(d)

Figure 5: Shock 2\%, Gini coefficient for wealth. Panel (a): total; (b): bottom 50\%; (c): middle 40\%; (d): top 10\%. Blue line: no shock; red line: shock at $t=301$. Averages over 100 simulations.

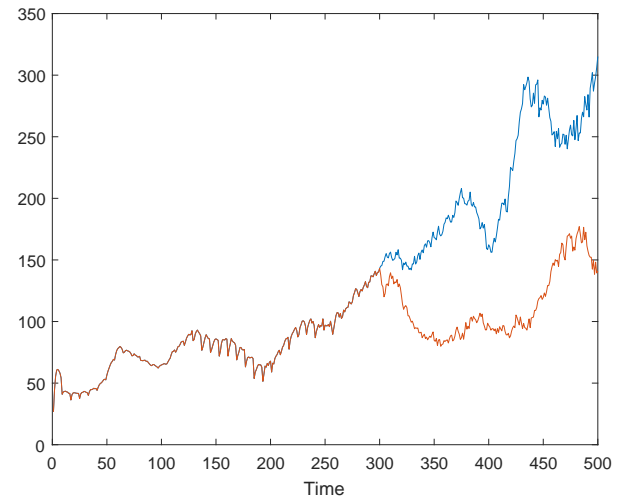

(a)

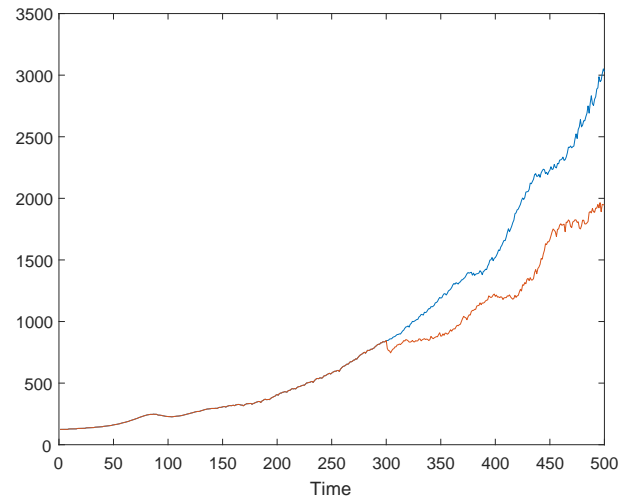

(b)

Figure 6: Shock 2\%, Ratio SS. Panel (a): wealth; (b): income. Blue line: no shock; red line: shock at $t=301$. Averages over 100 simulations. 
and then a somewhat erratic increase. These wide fluctuations are probably due also to the smaller size of the group.

Increasing income inequality then reverberates also on wealth inequality (which we do not report).

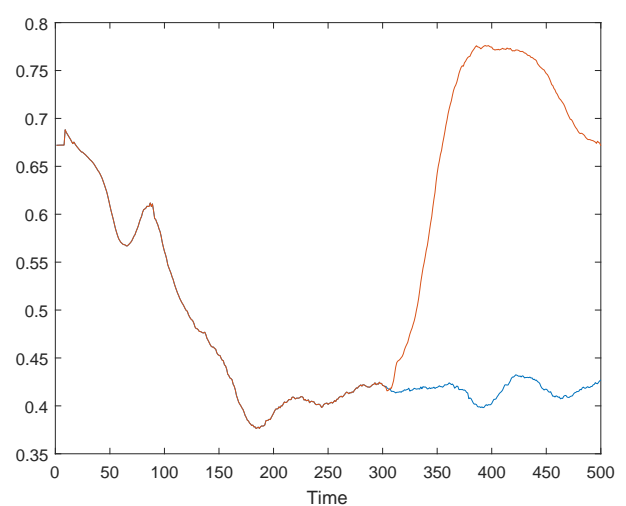

(a)

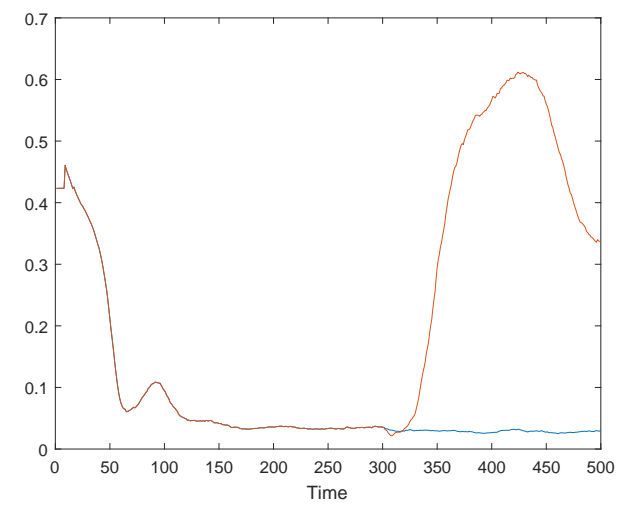

(c)

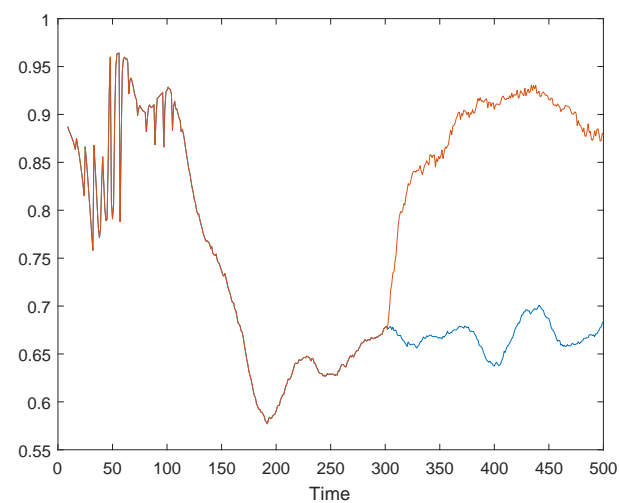

(b)

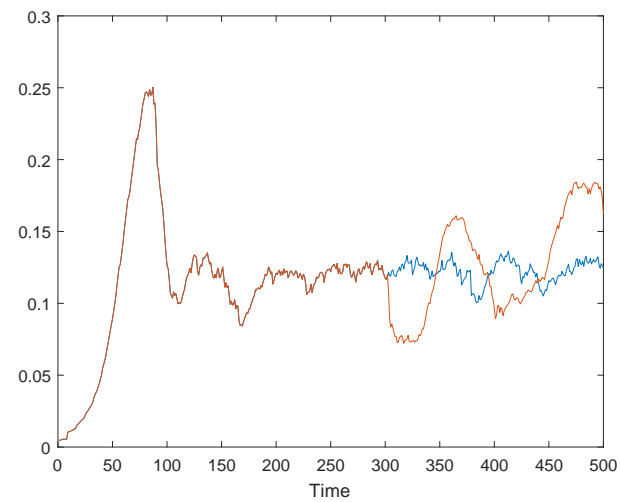

(d)

Figure 7: Shock 4\%, Gini coefficient for income. Panel (a): total; (b): bottom 50\%; (c): middle 40\%; (d): top 10\%. Blue line: no shock; red line: shock at $t=301$. Averages over 100 simulations.

To summarize, when wages decrease, also their dispersion decreases, which leads to an overall decrease in inequality for the $40 \%$ and $10 \%$ groups in the first "low-rate" scenario (fig. 4), when capital income does not increase much. Conversely, in the "high-rate" scenario (fig. 7) the increase in capital income inequality becomes the driving force, as the change in monetary policy is more pronounced. As a consequence, in the long-run inequality surges for both groups.

In conclusion, the two experiments suggest that monetary policy may exert a non-linear effect on inequality. Thus, in the next Section we will further investigate this hypothesis through a local sensitivity analysis. 


\subsection{Local sensitivity analysis}

In this Section we analyze the behavior of inequality for increasing values of the policy rate $i_{t}$. For each value of the interest rate we run 100 independent simulations of 500 periods; for each simulation $i$ we compute the average Gini coefficient $g_{i}$ relative to the variables of interest and then we take the average $\bar{g}=100^{-1} \sum_{i} g_{i}$ across simulations.

Panel (a) of Figures 8 and 9 confirms our hypothesis of a non-linear relationship between monetary policy and inequality: as $i_{t}$ raises from $0.5 \%$ to $5 \%$ with increments of $0.5 \%$, in fact, inequality first decreases reaching a minimum at $i_{t}=2 \%$ and then starts raising. Moreover, a visual inspection of Panels (b) and (c) reveals that the behavior of the total Gini index is probably driven by the Gini indexes relative to the bottom $50 \%$ and middle $40 \%$ groups, whereas the richest group behaves somewhat differently. Panel 8(d) shows in fact that for the richest $10 \%$ income inequality decreases, before stabilizing around a slightly lower level (from about 0.12 to about 0.1 ). The initial decrease is consistent with the outcome of the first policy experiment showed in Panel 4(d), whereas the subsequent stabilization may be due to the fact that, at high interest rates regimes, labor income loses relevance for the top $10 \%$ group and that, consequently, increasing wage inequality does not affect the Gini index. The decrease in inequality for the rich is even more evident in the case of wealth (Panel 9(d)). Basically, more restrictive monetary policy regimes increase both income and wealth inequality for the totality of households but reduce them within the richest group. We point out that this result is compatible with findings reported in Davtyan (2017), according to which expansionary monetary policy reduces inequality only if the top $1 \%$ households are not included in the analysis.

\subsection{Global sensitivity analysis}

Experiments conducted in Sections 4.1 and 4.2 involve solely changes in the policy rate, whereas other parameters are kept fixed at their baseline values. The strength of global sensitivity analysis is that it allows to assess how the parameters interact with each other. The goal of this Section is therefore to investigate the distributive consequences of monetary policy controlling in particular for the bank's lending attitude, captured by parameters $\theta$ and $\tau$. Moreover, as additional controls, we will allow also other parameters to vary, namely the job contract duration $D$, the marginal propensity to consume $c$ and the recapitalization coefficient $\psi$ (see Section 2.2).

We will first illustrate our computationally-light method to perform global sensitivity analysis in Section 4.3, and then we will report our findings in Section 4.3.

\section{The general procedure}

Consider a statistic $s$ computed on the output of a single simulation of the agent-based model. This statistic will be a function of initial conditions $A_{0}$, model parameters $\gamma$ belonging to the parameter space $\Gamma$ and random numbers $r$ :

$$
s=s\left(A_{0}, \gamma, r\right) \text {. }
$$




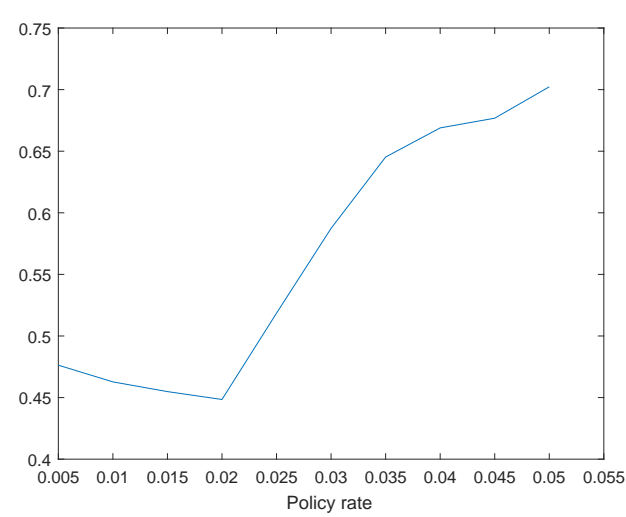

(a)

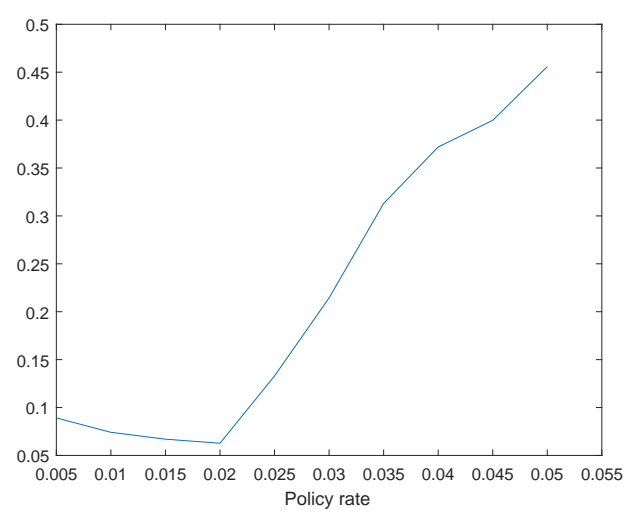

(c)

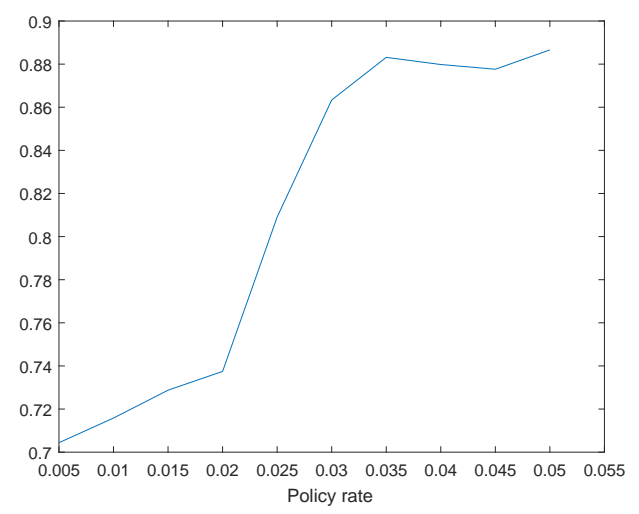

(b)

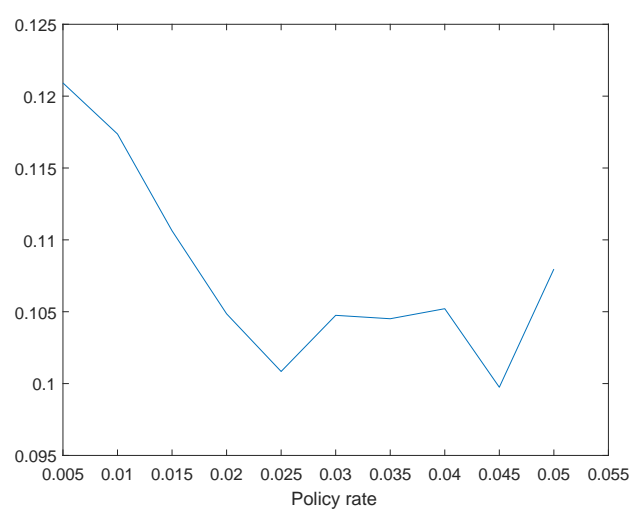

(d)

Figure 8: Gini coefficient for income. Panel (a): total; (b): bottom 50\%; (c): middle 40\%; (d): top 10\%. Averages over 100 simulations. 


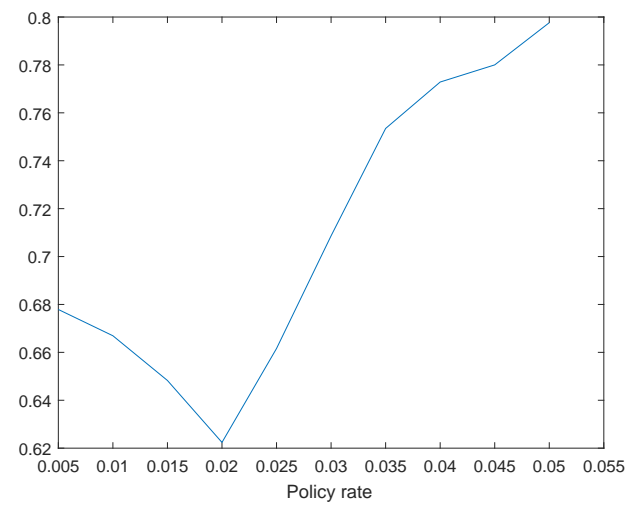

(a)

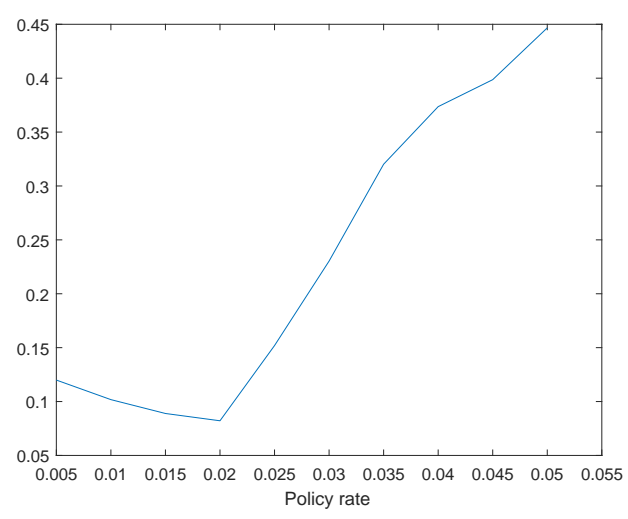

(c)

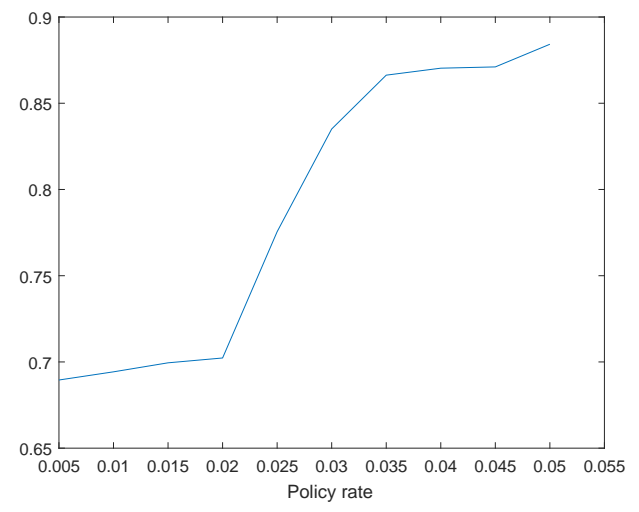

(b)

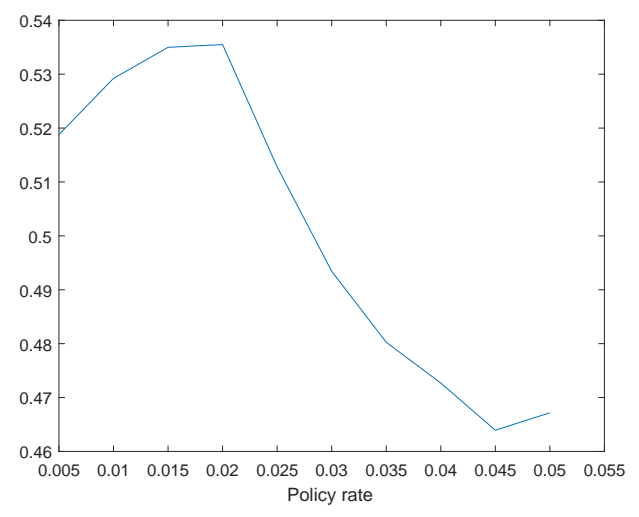

(d)

Figure 9: Gini coefficient for wealth. Panel (a): total; (b): bottom 50\%; (c): middle 40\%; (d): top 10\%. Averages over 100 simulations. 
Suppose to be interested in measuring the effect of the $\gamma$ 's on $s$. To this scope we can estimate the auxiliary regression meta-model

$$
s=\beta \gamma+u(r),
$$

where the meta-parameters $\beta$ measure the linear effect of the model parameters $\gamma$ on $s .{ }^{6}$ The regression error $u$ may depend on the initial conditions, on the stream of random numbers and, possibly, on the model parameters (if the relationship with $s$ is non-linear). For simplicity, though, we suppose that the error does not depend on $\gamma$. In addition, we suppose that we are not interested in the initial conditions (if the data generating process of the model is ergodic, this is just a natural assumption).

As a first step to the estimation of Eq. (26) we have to generate $n$ vectors $\gamma_{i}$ randomly sampled from the parameter space $\Gamma$. Then, we simulate the model $n$ times - one for each of the vectors $\gamma_{i}$ - obtaining $n$ values $s_{i}$ for the statistic of interest. Consequently, we can estimate Eq. (26) by OLS using the samples for $s$ and for the parameters, obtaining

$$
\hat{s}=\hat{\beta} \gamma
$$

The OLS estimates $\hat{\beta}$ will certainly depend on the particular stream of random numbers $r$ used during the simulation of the model. Hence, in order to get rid of the influence of $r$, for each parameter vector $\gamma_{i}$ a number $k$ of Monte Carlo replications have to be performed so that the average $k^{-1} \sum_{k} \hat{\beta}_{k}$ can be taken. Consequently, one has to run the model $n \cdot k$ times.

What we have just illustrated is a procedure which can be computationally demanding. The approach we are going to employ is simpler than the one described above as it requires only $n$ simulations. Basically, we hold that there is no need to run $k$ Monte Carlo simulations for each parameter vector to eliminate the effect of the random numbers $r$. In fact, when we sample the $n$ vectors $\gamma_{i}$, at the same time we can randomly sample also $n$ streams of numbers $r_{i},{ }^{7}$ and then we estimate the relationship

$$
s_{i}=\beta \gamma_{i}+u\left(r_{i}\right), \forall i=1 \ldots n
$$

Just like in Eq. (26), by construction the error term of the meta-model will depend on the unobserved stream of random numbers $r_{i}$. The difference now is that we can regard the numbers $r_{i}$ in Eq. (28) simply as an omitted explanatory variable influencing $s_{i}$ through the error term. But as the stream $r_{i}$ was randomly selected, it is uncorrelated with the regressors $\gamma_{i}$ and, therefore, its omission from the equation does not generate correlation between the error $u_{i}$ and $\gamma_{i}$. Hence, maintaining the assumption that the regression model (28) is not misspecified, the OLS estimators $\hat{\beta}$ applied to it are consistent for $n \rightarrow+\infty$.

\footnotetext{
6 This is a simple implementation of the Kriging meta-modeling approach. Relatively to agent-based economics, see for instance Bargigli et al. (2018) and Dosi et al. (2018).

7 In practice, when for a given $\gamma_{i}$ we run a simulation of the model to generate the corresponding $s_{i}$, we randomly choose the seed of the random number generator.
} 


\section{Results}

In this Section we are going to apply the approach explained above to the equation

$$
s=\beta \gamma+u,
$$

where $s$ is the income Gini index and $\gamma=\left(i_{t}, \theta, \tau, D, \psi, c\right)^{\prime}$ (similar results are obtained for wealth, so we are not going to report them). For each parameter we restrict the corresponding parameter space $\Gamma$ to a suitable range of values, as summarized by Table 6 . From the parameter space we randomly draw 500 parameter vectors $\gamma_{i}$ and run the model 500 times (so, $n=500$ ), choosing randomly also the seed of the random number generator. Then, for each simulation we take the average Gini coefficients after discarding the first 100 periods.

Column (1) of Table 7 reports the results relative to the income Gini coefficient computed for all the households. Overall, the meta-model explains almost the 50\% of the Gini coefficient variability and, therefore, can be considered informative enough (as for wealth inequality, the $R^{2}$ is even larger). Consistently with our previous findings, a more restrictive monetary policy (higher rate $i_{t}$ ) increases income inequality. Inequality is also increased by a stricter lending policy by the bank (higher $\theta$ ), while decreases when the debts are to be repaid more quickly (higher $\tau$ ). Moreover, longer job contracts reduce inequality, whereas a higher recapitalization coefficient and marginal propensity to consume increase it. All the estimated coefficients are statistically different from zero, except for $\psi$.

Now, in order to discover how the distributive properties of monetary policy are affected by the bank's behavior, we augment the basic model by adding the interaction terms of the policy rate with $\theta$ and $\tau$. Column (2) of Table 7 reports the results, which confirm our previous findings. In addition, we can see that the effect of $i_{t}$ on the Gini index is attenuated by a more restrictive bank's lending attitude (the estimated coefficient on $i_{t} \cdot \theta$ is negative). This means that changes in monetary policy may have a stronger impact on inequality during normal times than during recessions, when commercial banks are more reluctant to make loans. Notice that, although the two interaction terms are not individually significant (probably because their introduction generates multicollinearity), they turn out to be jointly significant when performing $F$ tests with the other parameters.

Our analysis can be refined by estimating the complete model with the interaction terms also for the usual three sub-groups of households: bottom 50\%, middle $40 \%$ and top $10 \%$. Table 8 shows that rising interest rates increase income inequality for the bottom class and, in particular,

\begin{tabular}{|ccc|}
\hline Parameter & N. of values & Range \\
$i_{t}$ & 100 & {$[0.001-0.05]$} \\
$\theta$ & 100 & {$[0.2-0.9]$} \\
$\tau$ & 100 & {$[0.01-0.2]$} \\
$D$ & 14 & {$[1-14]$} \\
$\psi$ & 100 & {$[0.005-0.2]$} \\
$c$ & 100 & {$[0.1-0.99]$} \\
\hline
\end{tabular}

Table 6: Parameter space. 


\begin{tabular}{|ccc|}
\hline Regressors & $(1)$ & $(2)$ \\
\hline$i_{t}$ & $5.11185^{* * *}$ & $6.85907^{* * *}$ \\
& $(.4196)$ & $(1.40744)$ \\
$\theta$ & $.38738^{* * *}$ & $.44829^{* * *}$ \\
& $(.02888)$ & $(.061083)$ \\
$\tau$ & $-.36972^{* * *}$ & -.23129 \\
& $(.10946)$ & $(.22761)$ \\
$D$ & $-.00756^{* * *}$ & $-.00749^{* * *}$ \\
& $(.00149)$ & $(.0015)$ \\
$\psi$ & .09282 & .09511 \\
& $(.10572)$ & $(.1058)$ \\
$c$ & $.17731^{* * *}$ & $.1784^{* * *}$ \\
& $(.02359)$ & $(.02361)$ \\
$i_{t} \cdot \theta$ & - & -2.29057 \\
& & $(2.0702)$ \\
$i_{t} \cdot \tau$ & - & -5.04173 \\
& & $(7.73829)$ \\
constant & .2953 & .24743 \\
& $(.02945)$ & $(.04714)$ \\
\hline$R^{2}$ & 0.4898 & 0.4915 \\
\hline
\end{tabular}

Table 7: Dependent variable: income Gini index. Observations $=500$. Significant at $1 \%$ : $^{* *}$.

\begin{tabular}{|cccc|}
\hline Regressors & $(1)$ & $(2)$ & $(3)$ \\
\hline$i_{t}$ & $3.06367^{* * *}$ & $11.7852^{* * *}$ & -.94368 \\
& $(1.08758)$ & $(2.2985)$ & $(.88026)$ \\
$\theta$ & $.22586^{* * *}$ & $.75475^{* * *}$ & $.13804^{* * *}$ \\
& $(.0472)$ & $(.09975)$ & $(.0382)$ \\
$\tau$ & -.2310 & .02182 & .08023 \\
& $(.17588)$ & $(.37172)$ & $(.14236)$ \\
$D$ & $.0025^{* *}$ & $-.0087^{* * *}$ & $.00336^{* * *}$ \\
& $(.00116)$ & $(.00245)$ & $(.00094)$ \\
$\psi$ & $.27582^{* * *}$ & .08684 & $-.29696^{* * *}$ \\
& $(.08175)$ & $(.17278)$ & $(.06617)$ \\
$c$ & $.26373^{* * *}$ & $.32139^{* * *}$ & $.18745^{* * *}$ \\
& $(.01825)$ & $(.03856)$ & $(.01477)$ \\
$i_{t} \cdot \theta$ & -1.25337 & -1.93154 & $6.25041^{* * *}$ \\
& $(1.59972)$ & $(3.38087)$ & $(1.29478)$ \\
$i_{t} \cdot \tau$ & .020356 & -16.52367 & -7.55663 \\
& $(5.97967)$ & $(12.63749)$ & $(4.8398)$ \\
constant & .4472 & -.35583 & -.08137 \\
& $(.03643)$ & $(.07699)$ & $(.02948)$ \\
\hline$R^{2}$ & 0.4494 & 0.5259 & 0.5480 \\
\hline
\end{tabular}

Table 8: Dependent variable: income Gini index. Column (1): bottom 50\%; column (2): middle 40\%; column (3): top $10 \%$. Observations $=500$. Significant at $1 \%:^{* *}$; significant at $5 \%:^{* *}$. 
for the middle class, whereas the effect is null or even negative for the top class. These results are again consistent with our previous findings. Moreover, we can notice the asymmetric effect of the bank's lending attitude: a more restrictive monetary policy increases the top class income inequality more when the bank's willingness to lend is lower (the estimated coefficient on $i_{t} \cdot \theta$ is positive), while the opposite is true for the other two classes.

In conclusion, a more restrictive monetary policy appears to increase overall income inequality, but this effect is different according to the sub-group considered. Moreover, the distributional properties of monetary policy seem to be affected by the bank's lending attitude.

\section{Conclusive remarks}

Recent empirical studies have pointed out that monetary policy may significantly affect income and wealth inequality through several channels. This influence is exerted not only because monetary policy can affect different income sources in different ways, but also because households are heterogeneous with regards to the relative size of their income sources.

Despite its relevance, this subject has gone relatively ignored by economic theory, mainly because the use of representative agents makes mainstream models inadequate to assess distributions and inequality (with the recent exception of the HANK models). To properly investigate the distributive properties of monetary policy, therefore, in this paper we resort to agent-based techniques in which agents' heterogeneity plays a fundamental role. The theoretical framework we set up is an agent-based macroeconomic model where firms, households and one bank interact on the basis of limited information and adaptive rules-of-thumb. Simulations show that the model is able to replicate fairly well a number of stylized facts, specially those relative to the business cycle.

Subsequently, we employ the model as a computational laboratory through which we can simulate changes in monetary policy and assess their influence on income and wealth inequality. Our analysis is three-fold. As a preliminary step we simulate a monetary policy shock that consists in a rise of the policy interest rate occurring in the course of a single simulation. The second step is to perform Monte Carlo experiments involving the policy rate only. Finally, we carry out a global sensitivity analysis exercise in order to control for other parameters, in particular to evaluate possible interactions between the monetary policy and the credit policy adopted by the banking system. We point out that the last kind of analysis is implemented through a novel methodology which greatly reduces the computational burden of simulations.

Consistently with part of the empirical literature, from all the three experiments the robust result emerges that a more restrictive monetary policy increases economic inequality, the main reasons being increasing unemployment and increasing capital income. This is an interesting result as it suggests that the social responsibility of central banks may go beyond their role of keeping price stability and that inequality can be a very important information for central bankers when they set their policy goals. Moreover, our finding could even constitute an argument in favor of a more democratic control of monetary policy actions.

Moreover, we find that the effect of monetary policy on inequality seems to be smaller when the bank's willingness to lend is lower. This entails that the ability of monetary policy to affect 
inequality may be reduced during recessions, when "credit crunches" are more likely to occur. As a consequence, fears of possible distortionary effects caused by expansionary monetary policy interventions may be unmotivated if the economy is in recession.

Finally, our analysis highlights that the influence of monetary policy on inequality is asymmetric, as different groups of households are hit by policy shocks in different ways. In particular, a restrictive monetary policy appears to increase inequality for the lower and middle-income classes, but not for the top class. This additional insight hints that it could be useful for empirical studies to focus not only on the whole population of households but also on sub-groups.

Although rich enough to provide non-trivial insights, we concede that our model suffers from some important limitations such as the absence of households' debts and more diversified portfolio investment opportunities. However, the introduction of these features is left for future works.

Acknowledgements We gratefully acknowledge the financial support by the Natural Science Foundation of Guangdong Province, under Grant No. 2018A030310148. Moreover, we thank two referees for their helpful comments and all the participants to EconWorld2018@ Amsterdam Conference, Amsterdam, July 2018.

\section{References}

Albanesi, S. (2007). Inflation and inequality. Journal of Monetary Economics, 54(4), 1088-1114.

http://www.sciencedirect.com/science/article/pii/S0304-3932(06)00212-1

Alesina, A., Summers, L. H. (1993). Central bank independence and macroeconomic performance: some comparative evidence. Journal of Money, Credit and Banking, 25, 151-162. http://www.jstor.org/stable/2077833

Areosa, W. D., Areosa, M. B. M. (2016). The inequality channel of monetary transmission. Journal of Macroeconomics, 48, 214-230. http://dx.doi.org/10.1016/j.jmacro.2016.03.004

Assenza, T., Delli Gatti, D., Grazzini, J. (2015). Emergent dynamics of a macroeconomic agent based model with capital and credit. Journal of Economic Dynamics and Control, 50, 5-28. https://doi.org/10.1016/j.jedc.2014.07.001

Bank of England (2012). The distributional effects of asset purchases. Quarterly Bulletin, 3, 254-266.

Bargigli, L., Riccetti, L., Russo, A., Gallegati, M. (2018). Network calibration and metamodeling of a financial accelerator agent based model. Journal of Economic Interaction and Coordination.

https://doi.org/10.1007/s11403-018-0217-8

Bernanke, B., Gertler, M. (1989). Financial fragility and economic performance. Quarterly Journal of Economics, 105, 87-114. http://www.jstor.org/stable/2937820

Bernanke, B., Gertler, M. (1990). Agency costs, net worth, and business fluctuations. American Economic Review, 79, 14-31. http://www.jstor.org/stable/1804770

Bernanke, B., Gertler, M. (1995). Inside the black box: the credit channel of monetary policy transmission. Journal of Economic Perspectives, 9(4), 27-48. https://www.aeaweb.org/articles?id=10.1257/jep.9.4.27

Bewely, T. (1999). Why wages don't fall during recessions. Cambridge, Harvard University Press.

Bhaskar, V., Machin, S., Reid, G. (1993). Price and quantity adjustment over the business cycle: evidence from survey data. Oxford Economic Paper 45, 257-268. http://www.jstor.org/stable/2663638

Blanchard, O. and Diamond, P. (1990). The cyclical behavior of the gross flows of U.S. workers. Brookings Papers on Economic Activity, 2, 85-143. http://www.jstor.org/stable/2534505

Caiani, A., Godin, A., Caversazi, E., Gallegati, M., Kinsella, S., Stiglitz, J. E. (2016). Agent based-stock flow consistent macroeconomics: towards a benchmark model. Journal of Economic Dynamics and Control, 69, 375-408.

https://www.sciencedirect.com/science/article/pii/S0165188915301020 
Campbell, C., Kamlani, K. (1997). The reasons for wage rigidity: evidence from a survey of firms. Quarterly Journal of Economics, 112, 759-789. http://www.jstor.org/stable/2951255

Chen, S., Desiderio, S. (2018). What moves the Beveridge curve and the Phillips curve: an agent-based analysis. Economics: The Open-Access, Open-Assessment E-Journal, 12 (2018-2), 1-30. http://dx.doi.org/10.5018/economics-ejournal.ja.2010-26

Cincotti, S., Raberto, M., Teglio, A. (2010). Credit money and macroeconomic instability in the agent-based model and simulator Eurace. Economics: The Open-Access, Open-Assessment E-Journal, 4 (2010-26). doi:10.5018/economicsejournal.ja.2010-26. http://www.economics-ejournal.org/economics/journalarticles/2018-2

Coibion, O., Gorodnichenko, Y., Kueng, L., Silvia, J. (2017). Innocent bystanders? monetary policy and inequality. Journal of Monetary Economics, 88, 70-89. http://dx.doi.org/10.1016/j.jmoneco.2017.05.005

Daly, M. C., Hobijn, B., Ni, T. (2013). The path of wage growth and unemployment. Federal Reserve Bank of San Francisco Economic Letter, July 15.

https://www.frbsf.org/economic-research/publications/economic-letter/2013/july/wages-unemployment-rate/

Davis, S., Haltiwanger, J., Schuh, S. (1996). Job creation and destruction. MIT Press, Cambridge, MA.

Davtyan, K. (2017). The distributive effect of monetary policy: The top one percent makes the difference. Economic Modelling, 65, 106-118. http://dx.doi.org/10.1016/j.econmod.2017.05.011

Delli Gatti, D., Desiderio, S. (2015). Monetary policy experiments in an agent-based model with financial frictions. Journal of Economic Interaction and Coordination, 10(2), 265-286. https://link.springer.com/article/10.1007/s11403-014-0123-7

Delli Gatti, D., Desiderio, S., Gaffeo, E., Gallegati, M., Cirillo, P. (2011). Macroeconomics from the bottom-up. Springer, Milan.

Desiderio, S., Chen, S. (2016). Why the rich become richer: insights from an agent-based model. International Journal of Computational Economics and Econometrics, 6, 258-275. http://www.inderscience.com/link.php?id=77249

Doepke, M., Schneider, M. (2006). Inflation and the redistribution of nominal wealth. Journal of Political Economy, 114(6), 1069-1097. http://dx.doi.org/10.1086/508379

Dosi, G., Fagiolo, G., Napoletano, M., Roventini, A. (2013). Income distribution, credit and fiscal policies in an agent-based Keynesian model. Journal of Economic Dynamics and Control, 37, 1598-1625. https://doi.org/10.1016/j.jedc.2012.11.008

Dosi, G., Fagiolo, G., Napoletano, M., Roventini, A., Treibich, T. (2015). Fiscal and monetary policies in complex evolving economies. Journal of Economic Dynamics and Control, 52, 166-189. http://dx.doi.org/10.1016/j.jedc.2014.11.014

Dosi, G., Pereira, M. C., Virgillito, M. E. (2018). On the robustness of the fat-tailed distribution of firm growth rates: a global sensitivity analysis. Journal of Economic Interaction and Coordination, 13, 173-193.

https://doi.org/10.1007/s11403-017-0193-4

Erosa, A., Ventura, G. (2002). On inflation as a regressive consumption tax. Journal of Monetary Economics, 49(4), 761-795. http://www.sciencedirect.com/science/article/pii/S0304-3932(02)00115-0

Geroski, P. (1991). Market dynamics and entry. Oxford, Basil Blackwell.

Gornemann, N., Kuester, K., Nakajima, M. (2012). Monetary policy with heterogeneous agents. Federal Reserve Bank of Philadelphia Working Papers, 12(21), 1-48.

http://www.philadelphiafed.org/research-and-data/publications/working-papers/2012/wp12-21.pdf

Gornemann, N., Kuester, K., Nakajima, M. (2016). Doves for the rich, hawks for the poor? Distributional consequences of monetary policy. International Finance Discussion Papers 1167, Board of Governors of the Federal Reserve System (U.S.). http://www.federalreserve.gov/econresdata/ifdp/2016/files/ifdp1167.pdf

Kaplan, G., Moll, B., Violante, G. L. (2016). Monetary policy according to HANK. Working Paper 1602, Council on Economic Policies.

https://www.cepweb.org/wp-content/uploads/CEP-WP-2016-2-Monetary-Policy-According-to-HANK.pdf 
Kawasaki, S., McMillan, J., Zimmerman, K. (1982). Disequilibrium dynamics: an empirical study. American Economic Review, 72, 992-1004. http://www.jstor.org/stable/1812018

Myers, S.C., Majluf, N.S. (1984). Corporate financing and investment decisions when firms have information that investors do not have. Journal of Financial Economics, 13, 87-224. https://doi.org/10.1016/0304-405X(84)90023-0

Mumtaz, H., Theophilopoulou, A. (2017). The impact of monetary policy on inequality in the UK. An empirical analysis. European Economic Review, 98, 410-423. http://dx.doi.org/10.1016/j.euroecorev.2017.07.008

Nakajima, M. (2015). The redistributive consequences of monetary policy. Federal Reserve Bank of Philadelphia Business Review (Second Quarter 2015). https://www.philadelphiafed.org/-/media/research-and-data/publications/ business-review/2015/q2/brQ215_the_redistributive_consequences_of_monetary_policy.pdf

Piketty, T. (2014). Capital in the twenty-first century. The Belknap Press of Harward University Press, Cambridge (MA)-London.

Riccetti, L., Russo, A., Gallegati, M. (2015). An agent-based decentralized matching macroeconomic model. Journal of Economic Interaction and Coordination, 10(2), 305-332.

https://link.springer.com/article/10.1007/s11403-014-0130-8

Riccetti, L., Russo, A., Gallegati, M. (2016). Financialisation and crisis in an agent based macroeconomic model. Economic Modelling, 52, 162-172. https://doi.org/10.1016/j.econmod.2014.11.028

Romer, C. D., Romer, D. (1999). Monetary policy and the well-being of the poor. Economic Review, Federal Reserve Bank of Kansas City, issue QI, 21-49. http://www.kansascityfed.org/publicat/econrev/PDF/1q99romr.pdf

Russo, A., Riccetti, L., Gallegati, M. (2016). Increasing inequality, consumer credit and financial fragility in an agent based macroeconomic model. Journal of Evolutionary Economics, 26(1), 25-47.

http://link.springer.com/10.1007/s00191-015-0410-z

Sterk, V., Ravn, M. (2017). Macroeconomic fluctuations with HANK \& SAM: an analytical approach. 2017 Meeting Papers 1067, Society for Economic Dynamics. https://economicdynamics.org/meetpapers/2017/paper_1067.pdf 


\section{Economics}

Please note:

You are most sincerely encouraged to participate in the open assessment of this article. You can do so by either recommending the article or by posting your comments.

\section{Please go to:}

http://dx.doi.org/10.5018/economics-ejournal.ja.2018-62

The Editor 